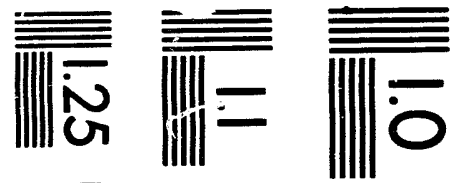

$$
\begin{aligned}
& \overline{\overline{\underline{\overline{|l| \mid}}}}
\end{aligned}
$$

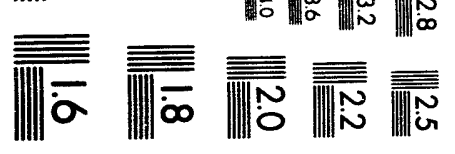



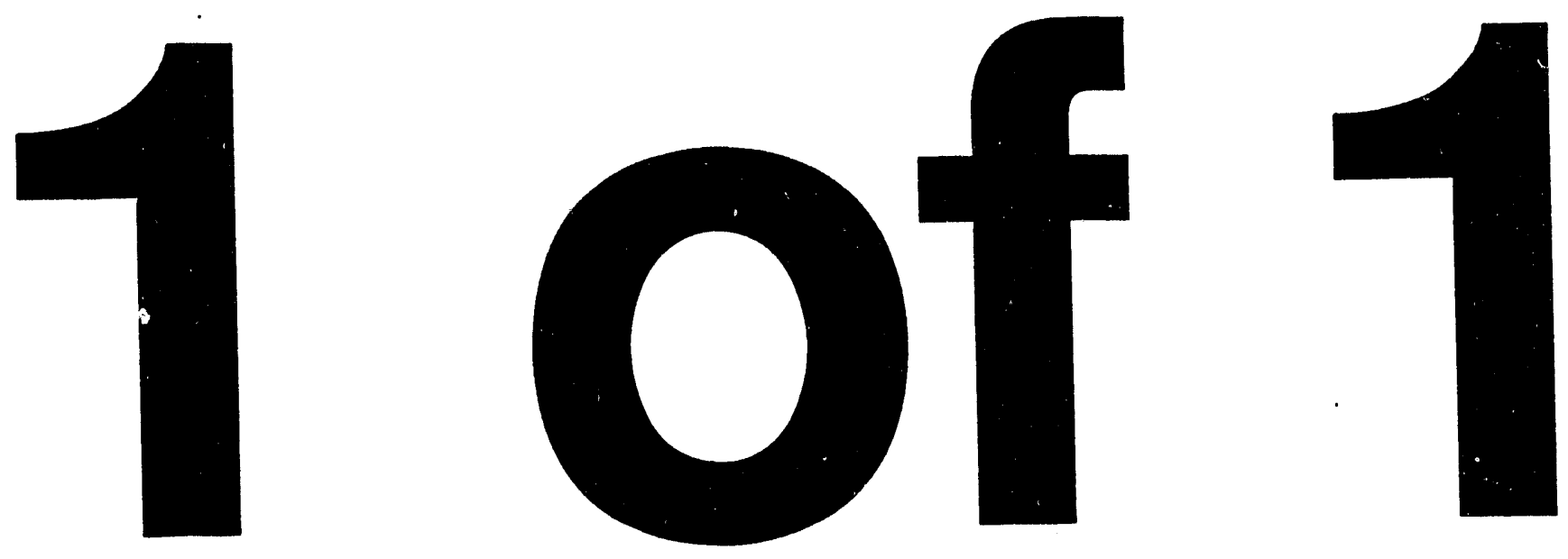


\title{
WALL CONDITIONING EXPERIMENTS ON TFTR USING IMPURITY PELLET INJECTION
}

\author{
BY
}

J.D. STRACHAN, D.K. MANSFIELD, M.G. BELL, ET AL.

NOVEMBER, 1993

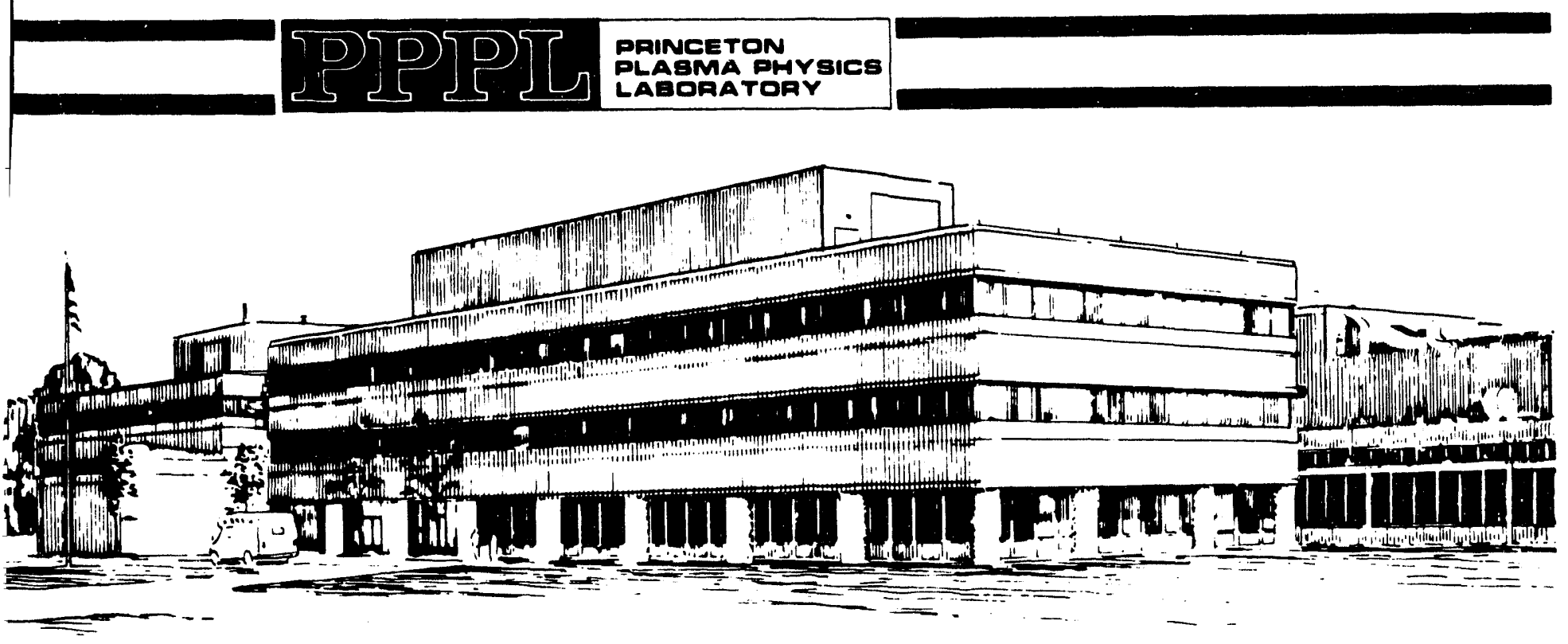




\section{NOTICE}

This report was prepared as an account of work sponsored by an agency of the United States Government. Neither the United States Government nor any agency thereof, nor any of their employees, makes any warranty, express or implied, or assumes any legal liability or responsibility for the accuracy, completeness, or usefulness of any information, apparatus, product, or process disclosed, or represents that its use would not infringe privately owned rights. Reference herein to any specific commercial produce, process, or service by trade name, trademark, manufacturer, or otherwise, does not necessarily constitute or imply its endorsement, recommendation, or favoring by the United States Government or any agency thereof. The views and opinions of authors expressed herein do not necessarily state or reflect those of the United States Government or any agency thereof.

\section{NOTICE}

This report has been reproduced from the best available copy.

Available in paper copy and microfiche.

Number of pages in this report: 37

DOE and DOE contractors can obtain copies of this report from:

Office of Scientific and Technical Information

P.O. Box 62

Oak Ridge, TN 37831;

(615) $576-8401$.

This report is publicly available from the:

National Technical Information Service

Department of Commerce 5285 Port Royal Road

Springfield, Virginia 22161

(703) $487-4650$ 


\title{
WALL CONDITIONING EXPERIMENTS ON TFTR USING IMPURITY PELLET INJECTION
}

\author{
J.D. Strachan, D.K. Mansfield, M.G. Bell, J. Collins, D. Ernst, K. Hill, J. Hosea, \\ J. Timberlake, M. Ulrickson, \\ Princeton University, Plasma Physics Laboratory \\ Princeton, NJ 08543 \\ and J. Terry, E. Marmar, J. Snipes \\ Plasma Fusion Center, MIT \\ Cambridge, MA 02139
}

\begin{abstract}
This work describes experiments intended to optimize the limiter conditioning for TFTR supershots. It is shown that deposition of thin layers of lithium on the limiters by impurity pellet injection changes the plasma-wall interaction and improves supershot performance. Series of up to ten Ohmic plasmas each with two lithium pellets were useful in pre-conditioning the limiter. Generally, plasma performance increased with the amount of lithium deposited up to the maximal amount which could be deposited. Experiments were performed with different materials being deposited (carbon, boron and lithium) and with different methods of deposition.
\end{abstract}




\section{INTRODUCTION}

TFTR supershot plasmas have confinement properties that are sensitive to the plasma-wall interaction and, therefore, to the condition or state of the limiter employed [1]. During the 1990 experimental run campaign, an effective technique for changing the plasma-wall interaction was found to be the deposition of thin, low-Z impurity films on the limiter by the ablation of injected impurity pellets $[2,3,4]$. This paper describes experimental efforts in the 1992 run campaign to enhance the energy confinement time of supershots by coating the carbon inner wall of TFTR with a sputter-deposited layer of boron or through the injection of lithium ( $\mathrm{Li})$, carbon $(\mathrm{C})$ or boron $(\mathrm{B})$ pellets into the plasma.

The improvements in supershot performance through the conditioning of the inner wall of TFTR have generally been higher energy confinement times, higher neutron emission, and higher $Q_{D D}$ values than have previously been observed in TFTR supershots. Also, because of the wall conditioning to be described below, plasma performance characteristic of supershots has been observed at higher plasma currents ( $\approx 2.4 \mathrm{MA}$ ) than was previously the case ( $\approx 1.9 \mathrm{MA}$ for the 1990 campaign). The physics details of the salutary effects of improved wall conditioning on plasma performance will be described more completely elsewhere [5]. It is the purpose of this work to describe the several empirical techniques of wall conditioning employed during the 1992 experimental campaign. In that regard, and in the interest of simplicity, emphasis will be placed upon the energy confinement time $\left(\tau_{E}\right.$, measured magnetically at the time of peak neutron production) as an indicator of improved plasma performance because it has been previously established that the plasma density, temperature and neutron emission rate all improve as the gross energy confinement time increases in TFTR supershots [6]. Spectroscopic features of the edge plasma emission as measured by a poloidal array of detectors have been used to characterize the influx of some of the principal constituents of the plasma $(D, C$, and $L i)$ and hence to draw 
inferences about the condition of the limiter surface in the experiments to be described below $[7,8]$.

The principal conclusions to be drawn from this work are that (1) wall conditioning with lithium improves supershot performance when increasing levels of lithium are introduced onto the limiter and (2) conditioning with combinations of $\mathrm{Li}$ and $\mathrm{C}$ pellets also shows promise. Several possibilities for further improvement of wall conditioning with injected impurities will be listed at the conclusion of this work.

\section{1992 IMPURITY WALL CONDITIONING EXPERIMENTS}

During the 1992 TFTR campaign seven experiments aimed at conditioning the inner wall were attempted. The parameters associated with these experimental sequences are summarized in Table 1. In all cases neutral beam injection (NBI) lasting $1 \mathrm{~s}$ began at $t=3.0 \mathrm{~s}$. An attempt to coat the inner wall of TFTR using three boron sputter sources comprised one of these experimental sequences and is discussed below. However, the principal device employed for wall conditioning was an impurity pellet injector [9]. This device was capable of injecting one or two impurity ( $\mathrm{Li}$, C or B) pellets into each TFTR discharge. Each cylindrical pellet could be as large as $2 \mathrm{~mm}$ dia $\times 2 \mathrm{~mm}$ long and each contained roughly enough impurity material ( $\approx 2 \times 10^{20}$ atoms) to lay down one geometric monolayer in the TFTR vacuum vessel. Because the two pellets could be fired independently, the time interval between injected pellets could be easily adjusted and was chosen to be as small as $0.1 \mathrm{~s}$. This minimum interval was dictated by the necessity for the plasma electrons to re-heat after the injection of the first pellet to a temperature high enough $(\approx 1$ $\mathrm{keV}$ ) to ensure that the second pellet injected would be completely ablated before reaching the TFTR inner wall. The pellet injector was relocated toroidally and underwent extensive modifications between the 1990 and the 1992 TFTR experimental run campaigns. The work repcrted below represents the initial attempt(s) to use the modified pellet injector. 
Sequence 1. Comparison of plasmas conditioned by lithium pellets to those without pellets.

The main goal of sequence 1 (shots 68200 - 68244, See Figs. 1-3) was to ascertain the number of pellet-conditioned plasmas required to bring into equilibrium the effects of the lithium film deposited on the surface of the inner wall. This sequence constituted the first use of $\mathrm{Li}$ pellets in 1992. As shown in Table 1, there were forty-one useful plasma attempts (i.e.: discharges without neutral beam injector faults) each with plasma current $\left(I_{p}\right)$ of $1.63 \mathrm{MA}$, injected beam power $(\mathrm{Pb})$ of $20.8 \mathrm{MW}$, toroidal magnetic field $\left(B_{t}\right)$ of $4.73 \mathrm{~T}$, and major radius $(R)$ of $2.45 \mathrm{~m}$. The shot sequence began with fourteen beam-heated plasmas without $L i$ pellets. There then followed a series of fifteen plasmas with two pellet injections attempted on each shot (at $2.2 \mathrm{~s}$ and $4.3 \mathrm{~s}$, i.e.: both before and after NBI). Of these fifteen plasmas, four had some neutral beam source failures and are not represented in Figs. 1-3. Of the eleven remaining shots, three shots had no pellets and two shots had only one pellet due to failures of the pellet injector. Thus, this part of the sequence displayed some variability in the amount of deposited lithium but did have a series in which six out of seven shots achieved the desired pellet firing sequence. There next followed a series of six shots without $\mathrm{Li}$ pellets. These shots were performed to study the erosion of the lithium from the limiter. This series was followed by eight shots each with pellets again injected at $2.2 \mathrm{~s}$ and $4.3 \mathrm{~s}$. This series reintroduced lithium onto the limiter in order to test the reproducibility of lithium conditioning. Finally, the sequence ended with three shots each with $\mathrm{Li}$ pellets injected at $2.0 \mathrm{~s}$ and $2.2 \mathrm{~s}$ (i.e.: both before NBI began). These particular shots (shots 68242-68244) featured more lithium injected into the beginning of the plasma and consequently had a higher lithium influx during the beamheating phase of the discharge. This is demonstrated by the elevated Lill emission level seen in Fig 3. Two of these plasmas had exceptionally high supershot energy confinement. There was an accompanying improvement in plasma performance with shot 68244 being among the best supershots ever produced in TFTR. Moreover, it has been found that most of the improvement exhibited by 68244 occurred in the plasma core with about a 
$50 \%$ reduction in the central particle diffusivity and a reduction in the ion thermal conductivity by a factor of 2-3. This shot is discussed in more detail elsewhere [5].

Sequence 1 documented the approach to equilibrium of the wallconditioning without the presence of lithium and demonstrated the approach to a new wall-conditioning equilibrium achieved by injecting a $\mathrm{Li}$ pellet both before and after beam-heating. The energy confinement time sporadically displayed an improvement of up to $40 \%$ with $\mathrm{Li}$ pellet conditioning (Fig. 1). As seen in Fig 1 , in the initial conditioning sequence, at the beginning of $\mathrm{NBI}$, ten to fifteen shots were required before the measured confinement times assumed a reproducible $( \pm 5 \%)$ level. As seen in Fig. 2, the Cll emission in the target plasma was reduced in the initial conditioning sequence as if the beam-heating, by itself, performed a conditioning process which reduced the influx of carbon from the limiter during the Ohmic phase of subsequent discharges. However, the $\mathrm{Cll}$ emission measured in the beam-heated phase was not influenced by this initial beam conditioning. The effects of conditioning the inner wall with lithium could be seen clearly during both the Ohmic/target and beamheated phases and were characterized by a generally decreased level of $\mathrm{Cll}$ emission indicating a reduction in carbon influx. In addition, the $D \alpha$ emission measured during beam-heating was reduced while the Lill emission level increased as a result of lithium conditioning.

\section{Sequence 2. Evaluation of Ohmic pre-conditioning discharges}

Sequence 2 (shots 68407-68426, See Fig. 4 ) was an attempt to observe the approach to equilibrium of the effects of $\mathrm{Li}$ pellets in Ohmic plasmas. This sequence was also used to pre-condition the limiter surface for the beam-heated experiments of sequence 3 which followed. In sequence 2, the first four discharges had no pellet injected, there then followed twelve discharges with two $\mathrm{Li}$ pellets injected and two discharges with only one pellet due to injector failures. The plasma current and discharge conditions were the same as for sequence 1 with the exception that these were Ohmic discharges. $\left(I_{p}=1.63 \mathrm{MA}, \mathrm{Bt}_{\mathrm{t}}=4.73 \mathrm{~T}\right.$, $R=2.45 \mathrm{~m}$, See Table 1). 
After about ten discharges with pellet injection, the Cll and $D \alpha$ emission reached their equilibrium values (Fig. 4) with the Cll emission being about $30 \%$ lower than before the lithium injection began. Lower levels of $\mathrm{Cll}$ emission in Ohmic target plasmas have been previously associated with better limiter conditioning and better plasma performance [1]. The tendency for the Ohmic plasmas (i.e.: those shots at the beginning of the sequence without $\mathrm{Li}$ pellet injection) to increase slightly in Cll emission is commonly seen after beam-heating sequences. It is probably the inverse effect to that seen at the beginning of the beamheating in sequence 1 , in which the $\mathrm{Cll}$ emission decreased.

Also seen in the insert to Fig. 4 are two density traces, one taken during the Ohmic phase before conditioning began and one taken near the end of the pellet sequence. All discharges were initiated with an identical pre-fill of deuterium gas. The reduced density level obtained after pellet conditioning is taken as a direct demonstration of the reduced effective recycling coefficient of the inner wall as a result of the deposited lithium layer.

Sequence 3 . Comparison of boron pellet conditioning to litrilum pellet conditioning.

This sequence (shots 68427-68488, See Figs. 5 and 6) contained fifty-five useful plasmas all having $\mathrm{I}_{\mathrm{p}}=1.63 \mathrm{MA}, \mathrm{Pb}=17.8 \mathrm{MW}, \mathrm{B}_{\mathrm{t}}=4.73$ $T$ and $R=2.45 \mathrm{~m}$ (Table 1 ). The machine parameters were the same as in sequence 1 except that the beam power was lowered from 20.8 MW to 17.8 MW to ensure that MHD events at the $\beta$ limit were avoided. There were another six plasmas in this sequence which experienced beam faults. These plasmas were dropped from consideration and are not represented in the data displayed.

There were three main purposes for this particular experimental sequence: (1) to observe the effects of an Ohmic pre-conditioning campaign (sequence 2) upon subsequent neutral beam-heated discharges (2) to compare the efficacy of Li pellets to that of B pellets and ( 3 ) to attempt to have the plasma benefit from four pellets injected before NBI rather than from merely two pellets. Toward these ends, the scenarios described below were carried out during sequence 3 . 
The initial beam-heated plasmas (shots 68427-68443) each had two Li pellets before $\mathrm{NBI}$ (at $20 \mathrm{~s}$ and $2.2 \mathrm{~s}$ ) although pellet injector railures occurred on four of these plasmas. This series of discharges was preceded by a series of Ohmic plasmas each having two injected $\mathrm{Li}$ pellets (sequence 2 as discussed). This Ohmic pre-conditioning was done in an attempt to influence the subsequent neutral beam-heated plasmas (sequence 3 ) by increasing the pre-deposited lithium layer. This scheme seemed to be effective because, despite some sporadic behavior, the beam-heated discharges immediately following the Ohmic preconditioning sequence exhibited both high confinernent times and high neutron emission rates (shots 68427-68443, Fig. 5). Further, the Lill emission in the Ohmic target plasma (just prior to beam-heating) and during the beam-heating phase were at their highest levels near the beginning of this sequence while the $\mathrm{Cll}$ emission (measured during beamheating) was at its lowest level (Fig. 6). It thus appears as if this conditioning sequence was most effective within five to ten shots of the end of Ohmic pre-conditioning and the start of neutral beam injection ( $\approx$ shots 68427-68432). The initial set of fifteen lithium-assisted beamheated plasmas was followed by nineteen beam-heated plasmas without $\mathrm{Li}$ pellets (shots 68444-68464). These plasmas were used to erode lithium from the TFTR limiter so as to allow a comparison of $\mathrm{Li}$ and $\mathrm{B}$ pellets. After roughly ten discharges, the lithium was removed (as indicated spectroscopically in Fig. 6) and the plasma confinement had stopped deteriorating (Fig. 5). This erosion rate was consistent with the erosion rate observed during sequence 1 .

After the lithium was removed from the limiter, there followed a series of plasmas into which $B$ pellets were injected (shots 68467$68478)$. The $B$ pellets were similar in size to the $L i$ pellets employed. There were ten plasmas with $B$ pellet injection attempted at $2.0 \mathrm{~s}$ and 2.2 $s$ (as was done for the preceding lithium-assisted plasmas). For five of these plasmas, only one pellet fired successfully. However, on the last three shots (shots 68476-68478) of this part of the sequence, both $B$ pellets were fired successfully. As can be seen in Fig. 5 , the influence of the boron on $\tau_{E}$ was a marginal improvement over the no-pellet shots and considerably less improvement compared to the lithium-assisted plasmas. Because there was a correspondingly small improvement in the neutron 
emission rate for these discharges, it is concluded that $\mathrm{Li}$ pellets are more effective than $B$ pellets at conditioning supershots.

Immediately following the boron experiments, a different scenario of $\mathrm{Li}$ pellet injection was employed (shots 68479-68486) wherein pellets were injected at $2.0 \mathrm{~s}$ and $2.2 \mathrm{~s}$ (i.e.: before $\mathrm{NBI}$ ) but only for discharges which had been preceded by a discharge in which pellets were injected at $3.9 \mathrm{~s}$ and $4.1 \mathrm{~s}$ (i.e.: after NBI). This was done in an attempt to make every other plasma experience the benefit of four $\mathrm{Li}$ pellets - the two pellets from the tail end of the previous discharge and the two injected immediately before NBI. This tactic thus dictated that alternating discharges experience a reduced effect from $\mathrm{Li}$ pellets (i.e.: obviously, in those discharges with injection taking place at $3.9 \mathrm{~s}$ and 4.1 $s$, no lithium could be deposited just before NBI). During this sequence, there were four plasmas which experienced the benefit from four pellets in the manner just described; however, the first of these had reduced neutral beam power. The plasmas assisted by four pellets were observed to be improving but were just beginning to reach the confinement, neutron emission, and lithium emission levels of the initial plasmas of the sequence when this particular experiment was terminated due to limitations on machine time. Evidently, the four-pellet approach has some promise but needs also to be preceded by about ten Ohmic pre-conditioning discharges. Also, there was considerable difference in performance between the plasmas assisted by four pellets and those that were not (i.e.: alternating discharges in the sequence 68482-68486, Fig. 5). This result strongly suggests that it is desirable to put as much lithium as possible into the plasma immediately before neutral beam injection.

Finally, the last shot of Sequence 3 (shot 68487) had one boron and one Li pellet injected at $2.0 \mathrm{~s}$ and $2.2 \mathrm{~s}$, respectively. This was done in an attempt to observe any synergistic effect which might be present when both materials were deposited on the limiter. This synergy might occur if any chemical compounds involving $\mathrm{C}, \mathrm{D}, \mathrm{Li}$ or $\mathrm{B}$ which formed on the limiter were playing a role in the enhanced supershot performance. However, the performance of this plasma was not noticeably enhanced over that of nearby plasmas. It is thus tentatively concluded that no strong synergistic effect was present. 
Sequence 4. Conditioning experiments at higher currents

This sequence (shots 69018-69044, See Fig. 7) was run at increased plasma current $\left(I_{p}=2.2 \mathrm{MA}\right)$ in order that the enhanced-confinement plasmas might have an extra margin of stability. Sequence 4 consisted of twenty-five plasmas. However, seven discharges suffered neutral beam faults and were dropped from consideration. Each of the remaining eighteen useful plasmas had parameters $\mathrm{Pb}=25.7 \mathrm{MW}, \mathrm{Bp}=5 \mathrm{~T}$, and $\mathrm{R}=$ $2.50 \mathrm{~m}$ (Table 1 ). The larger major radius was chosen to avoid an integral $q$ value at the limiter. The salient feature of sequence 4 is that a comparison was made between high-current plasmas influenced by two $\mathrm{Li}$ pellets injected immediately before beam-heating with those plasmas additionally influenced by two $\mathrm{Li}$ pellets injected at the end of the preceding plasma (shots 69035-69043, Fig. 7). This is the same comparison accomplished at lower current in a subsection of sequence 3 (shots 68479-6846, Fig. 5). Because alternating discharges in this section of sequence 4 are seen to have significantly different confinement times it is taken as strong reinforcement of the conclusion from sequence 3 that it is desirable to put as much lithium as possible into the plasma berore NBI.

Sequence 4 was preceded by thirteen Ohmic pre-conditioning discharges (shots 69004-69017, Fig. 7) each with one or two Li pellets injected; this was done in an attempt to reproduce the beneficial interaction that took place between sequences 2 and 3 . However, the preconditioning series run just before sequence 4 was complicated by the fact that it was part of an accelerated campaign to recover from a major disruption. On TFTR, such disruptions have the effect of reducing supershot performance by increasing the particle recycling coefficient of the limiter. Low recycling conditions are recovered only after extended (>30 shots) plasma operation. Thus, because the pre-conditioning campaign was abbreviated due to limitations on machine time, there can be no assurance that the limiter was optimally pre-conditioned prior to the start of sequence 4. However, because the lithium layer was not removed between pellet injection scenarios in sequence 4 , it is expected that the lithium built up in the preceding Ohmic plasmas allowed a equilibrium level of lithium to be established for both pellet injection scenarios. 
Even with these uncertainties, it can be seen in Fig. 7 that regardless of the details of pellet injection, so long as $\mathrm{Li}$ pellet conditioning was used, supershot-like confinement times $(\approx 0.10-0.15$ s) as weil as supershot plasma performance were obtained at $1 p=2.2 \mathrm{MA}$. This represents a significant increase in the plasma current at which supershots have been observed in TFTR. During the 1990 run, supershot performance could not be obtained above currents of $\approx 1.9 \mathrm{MA}$. In 1992, as a result of lithium conditioning, this upper limit was eventually extended to about 2.45 MA in experiments that are more completely described elsewhere [5].

\section{Sequence 5. Comparison of carbon and lithium conditioning}

During this sequence (shots 6910z-69128, See Fig. 8) conditioning with $C$ pellets was investigated and compared to conditioning with $\mathrm{Li}$ pellets. This sequence contained twenty-one useful plasmas and another seven plasmas with lower beam power due to source faults. The plasma conditions were $\mathrm{I} p=1.98 \mathrm{MA}, \mathrm{Pb}=25.5 \mathrm{MW}, \mathrm{Bt}=4.95 \mathrm{~T}$ and $\mathrm{R}=2.52 \mathrm{~m}$ (Table 1). The major radius was again chosen to avoid integral $q(a)$ values. Alternative $C$ injection was accomplished by either injection of the $C$ pellet late into the beam-heated phase of the plasma or by embedding a small $\mathrm{C}$ pellet in a larger $\mathrm{Li}$ pellet (thus forming a $\mathrm{Li} / \mathrm{C}$ or composite pellet). These tactics were employed because previous experiments had shown that the injection of $C$ pellets before NBI severely perturbed the plasma and therefore risked causing a disruption. In sequence 5 , the experiments essentially compared $\mathrm{Li}$ pellets to the combined injection of $\mathrm{Li}$ and $\mathrm{C}$. The rationale for performing these $\mathrm{C}$ pellet experiments was to simulate the beneficial effects of a carbon bloom. In 1990, it was observed that discharges which suffered a carbon bloom often caused improved plasma performance in the discharge immediately following the bloom [1].

The sequence of beam-heated plasmas was preceded by five Ohmic pre-conditioning plasmas (shots 69096-69101, Fig. 8) each having two injected $\mathrm{Li}$ pellets. There then followed a sequence of seven discharges with two $\mathrm{Li}$ pellets injected before NBI (shots 69102-69110, Fig. 8). These initial plasmas of sequence 5 had slightly higher Lill emission than 
did subsequent plasmas. There next followed a discharge into which one $C$ and one $\mathrm{Li}$ pellet were injected at $2.0 \mathrm{~s}$ and $2.4 \mathrm{~s}$, respectively. Carbon pellets were injected into the post-NBI phase of the next three discharges (shots 69113-69118, Fig. 8). Finally, four discharges were taken into which two $\mathrm{Li} / \mathrm{C}$ composite pellets were injected just before $\mathrm{NBI}$ and these discharges were compared to four discharges into which two Li pellets were injected (shots 69121-69124 and 69125-69128 respectively, Fig. 8 ). The four discharges with composite pellets were seen to have significantly higher confinement times than subsequent discharges with only $\mathrm{Li}$ injected. However, the reproducibility of this result was not tested due to limitations on machine time. It should also be pointed out the confinement times obtained with the composite pellets were shorter than the confinement times obtained with lithium conditioning in the beginning of sequence 8 (shots 69102 - 69110). However a direct comparison is difficult to make in this case because the initial discharges in this sequence were preceded by Ohmic pre-conditioning with Li pellets.

The plasmas conditioned with combinations of lithium and carbon had high $\tau_{E}$, high neutron emission rates, and high central density. On the basis of this brief comparison, it is thus concluded that further experiments should be undertaken to find the optimum combination of $\mathrm{Li}$ and $C$ pellet injection. In particular, the efficacy of composite pellets should be investigated in future experiments.

\section{Sequence 6. Moveinent of the plasma column}

This was another Ohmic sequence (shots 69129-69149, See Fig. 9) of fourteen useful 1.4 MA plasmas each having two $\mathrm{Li}$ pellets injected per plasma. In addition, this sequence featured the movement of the plasma column from the outboard limiter onto the inner wall limiter. During this series of discharges, the plasmas began and ended at $R=2.75$ interacting with the TFTR outboard limiter. At $t=2.0 \mathrm{~s}$ these plasmas were moved onto the inner wall limiter for $1.2 \mathrm{~s}$ during which time two $\mathrm{Li}$ pellets were injected (Fig. 9). This in-and-out movement (from $R=2.75 \mathrm{~m}$ to $R=$ $2.45 \mathrm{~m}$ to $R=2.75 \mathrm{~m}$ ) was done in an attempt to minimize the erosion of the freshly-deposited lithium by minimizing the duration of the plasmainner-wall interaction. As a result of this tactic, the $\mathrm{Cll}$ emission from 
the plasma decreased well below levels attained using other methods of $\mathrm{Li}$ pellet conditioning (Fig. 9). This decrease was observed after about ten Ohmic plasmas and, because of constraints on machine time, it is not clear that equilibrium was attained. Thus, this technique seems to hold promise and should be optimized in future experiments.

After completing a conditioning series in the manner described, the Lill emission level measured inımediately hefore $N B 1$ in the next target plasma (shot 69152, Fig. 10) was among the highest obtained in the 1992 campaign while the Cll emission was among the lowest. Although the plasma performance following this type of conditioning was good, it was not at the best level of performance which had been attained. The best 1992 supershot also occurred at $R=2.52 \mathrm{~m}, \mathrm{lp}=2.0 \mathrm{MA}$, but had $30.8 \mathrm{MW}$ of beam power as compared to the $26 \mathrm{MW}$ injected into shot 69152 .

It is interesting to note that immediately following this conditioning effort involving plasma movement, both the $\mathrm{Cll}$ and Lill emission levels in the Ohmic target plasma were at the respective magnitude associated with the best plasma performance (highest $\tau_{E}$ ) attained by TFTR. However, because the plasmas associated with these emission/influx levels did not attain the highest plasma performance, it is concluded that a reduction of carbon influx is necessary but not sufficient for the attainment of peak plasma performance.

Comparison of the time evolution of the plasma immediately after the initial $\mathrm{Li}$ pellet conditioning with the best TFTR supershot indicates that movement of the plasma during lithium deposition did attain the low edge density and Cll emission of the best TFTR plasmas but did not attain the same high central density [5].

\section{Sequence 7. Conditioning using boron sputter sources.}

In order to lay down a thicker layer of boron than could be achieved with the injection of B pellets, deposition with RF sputter sources was attempted [10]. Three sputter sources with pure boron targets were inserted into the TFTR vacuum vessel and each was operated at $1 \mathrm{~kW}$ of RF power for eight hours in a $5 \mathrm{mTorr}$ atmosphere of Helium. A total of $\approx 0.3$ $\mathrm{g}$ of boron was eroded from the targets which is larger than the $\approx 0.03 \mathrm{~g}$ typically deposited by a pair of $B$ pellets but is smaller than the $\approx 10 \mathrm{~g}$ 
typical of plasma-vapor deposition of boron fro $n$ diborane gas [11]. The potential advantage of the boron sputter deposition over boronization with diborane vapor is that, when the latter technique has been employed in the past, the TFTR limiters have been observed to retain large amounts of both hydrogen and deuterium (up to $40 \%$ ) making them incompatible with supershot operation. Also, while it has been found that the retained hydrogenic species can be removed by conditioning discharges, such discharges also remove the deposited boron [11]. As a result of the alternative method of boronization employed in sequence 7 , the limiters were not loaded with either hydrogen or deuterium so that the effects of a boron layer on supershot performance could potentially be assessed in a clearer fashion than was previously possible.

Residual helium embedded in the limiter is also incompatible with supershot plasma performance, thus plasma operation was suspended for several days after the boronization to allow helium to pump out of the TFTR vacuum vessel. This tactic seemed to succeed because, within seventy-two hours after boronization, the partial pressure of helium was as low as it was prior to the operation of the boron sputter probes. In addition, helium was not detected in the first plasmas after the boronization. Conversely, the water peak as measured by a residual gas analyzer was reduced by a factor of 3 due to boron sputtering but had risen to its initial value by the time of the resumption of plasma operation. This recovery in water vapor partial pressure was attributed to two small air leaks which occurred during the period of vessel inactivity following boronization. These leaks probably saturated the ability of the boron layer to adsorb oxygen. However, because oxygen is not an important impurity during TFTR supershot operation, these leaks were not considered serious enough to affect the assessment of boron sputtering on supershot performance.

After boronization and the subsequent helium pumpout period, the first two plasma attempts suffered hardware failures. This unfortunate circumstance made an unambiguous comparison with previous supershots problematic. However, eight of the next ten plasmas were supershot attempts with $\mathrm{I}_{\mathrm{p}}=2.0 \mathrm{MA}, \mathrm{Pb}=21.5 \mathrm{MW}, \mathrm{Bt}=4.8 \mathrm{~T}$ and $\mathrm{R}=2.45 \mathrm{~m}$ ( Table 1). These plasmas exhibited performance characteristics similar to 1990 supershot plasma attempts at the same machine settings (Fig. 11). 
Hence, as opposed to the immediate and profoundly beneficial effects of wall-conditioning with $\mathrm{Li}$ pellets, no such clear effects were observed when boron was deposited by either B pellets (sequence 3 ) or with RF sputter deposition (sequence 7). It thus appears that boron may not be as effective as lithium at improving supershot performance. The apparent ineffectiveness of boron sputtering as compared to $\mathrm{Li}$ pellet injection is not completely understood at present. It is possible that even though the amount of boron sputtered inside the vacuum vessel was large $(\approx 0.3 \mathrm{~g})$, the amount of boron actually deposited onto the limiter may have been much less. It is also possible that the method of impurity deposition by the plasma for pellets may play a role in the enhancement of plasma performance.

\section{DISCUSSION}

Empirical optimization of the $L i$ pellet conditioning of TFTR supershots represented a significant effort in the 1992 campaign. It was found that boron sputtering and boron pellets were not as successful as Li pellets at conditioning the limiters to enhance supershot performance.

Results of the 1992 run suggest that a near-optimal conditioning sequence on TFTR might be:

(a) ten Ohmic plasmas each with two Li pellets and contacting the inner wall limiter only while the lithium is being deposited on the limiter $(\approx 1 \mathrm{~s})$.

(b) five pairs of plasmas with NBI, alternating two pellets before the beams with two pellets after NBI. In this manner every other plasma would have the conditioning benefit of four pellets.

Further efforts at improving the pellet conditioning could still incorporate:

(a) the use of $C$ and Li pellets in combination,

(b) more and larger Li pellets,

(c) more extensive use of plasma motion to decrease the erosion of lithium from the limiter.

The plasma performance (neutron emission, confinerient time, and energy content) increases steadily with the lithium content on the limiter 
(Fig. 12). The improvement in the plasma performance associated with the $\mathrm{Li}$ pellet injection is correlated to changes in the same parameters that correlate with $\tau_{E}$ in supershots without Li pellets. The lithium seems associated with decreased hydrogen and carbon recycling both before and during the beam-heating (Fig. 13) $[1,12]$. There is also a strong correlation of $\tau_{E}$ at the time of peak neutron emission with the peakedness of the neutral beam deposition (Fig. 14) [13]. In this regard, the effect of the $\mathrm{Li}$ pellets seems more like an extension of the supershot plasma rather than a fundamentally new confinement regime.

The very best 1992 supershot plasma was preceded by a bloom-like event on the preceding plasma as had occurred in 1990 [5]. Since the C pellets give spectroscopic signals which are similar to the bloom events, further investigation of possible synergistic $\mathrm{Li}+\mathrm{C}$ pellet experiments are desirable. It may be possible to inject a $C$ pellet into the beam-heated phase of a preceding discharge to avoid the large perturbations which occurs when these pellets are injected into Ohmic discharges.

\section{ACKNOWLEDGMENTS}

This work was supported by the U.S. Department of Energy Contract No. DE-ACO2-76-CHO-3073. The authors wish to acknowledge the many contributions of M. Vocaturo toward the success of the pellet gun modifications. The authors also wish to thank the operational staff of TFTR. 


\section{REFERENCES}

[1] J.D. Strachan et al., J. Nucl. Mater. 196-198 (1992) 28.

[2] J. L. Terry et al., Proc. 11 th Int. Conf. on Plasma Physics and Controlled Nuclear Fusion Research, Washington, USA, 1990 ( IAEA, Vienna 1991) A-V-5.

[3] J. A. Snipes et al., Proc. 18th European Conf. on Controlled. Fusion and Plasma Physics, Berlin, Germany, (1991), Vol. 3 (EPS, Berlin,1991) 141.

[4] J. A. Snipes et al., J. Nucl. Mater. 196-198 (1992) 686.

[5] D. L. Jassby et al., Princeton Plasma Physics Laboratory Report No. PPPL-2940 (1993).

[6] J. D. Strachan et al., Princeton Plasma Physics Laboratory Report No. PPPL-2858 (1992).

[7] A. T. Ramsey and S. L. Turner, Rev. Sci. Instr. 58 (1987) 1211.

[8] K. Hill et al., (to be published in Bull. Am. Phys. Soc.).

[9] J. L. Terry, E. S. Marmar and R. B. Howell, Rev. Sci. Instr. 61 (1990) 2908.

[10] The boron sputter sources were manufactured by Angstrom Sciences of Pittsburgh, Pennsylvania.

[11] H. F. Dylla et al., J. Nucl. Mater. 176-177 (1990) 337.

[12] J. D. Strachan, Princeton Plasma Physics Laboratory Report No. PPPL-2933 (1992). 
[13] H. K. Park et al., Princeton Flasma Physics Laboratory Report No. PPPL-2944 (1993). 


\section{Table 1}

\begin{tabular}{|c|c|c|c|c|c|c|}
\hline Sequence & \#Shots & $I P(M A)$ & $\mathrm{Pb}_{b}(\mathrm{MW})$ & $B(T)$ & $\mathrm{R}(\mathrm{m})$ & Comments \\
\hline 1 & 41 & 1.63 & 20.8 & 4.73 & 2.45 & $\begin{array}{l}\text { Compare } \\
\mathrm{Li} / \text { no Li }\end{array}$ \\
\hline 2 & 18 & 1.63 & 0 & 4.73 & 2.45 & Ohmic \\
\hline 3 & 55 & 1.63 & 17.8 & 4.73 & 2.45 & $\begin{array}{l}\text { Compare } \\
\mathrm{Li} / \mathrm{B}\end{array}$ \\
\hline 4 & 18 & 2.20 & 25.7 & 5.00 & 2.50 & Higher Ip \\
\hline 5 & 21 & 1.98 & 25.5 & 4.95 & 2.52 & $\mathrm{Li}+\mathrm{C}$ pellets \\
\hline 6 & 14 & 1.4 & 0 & 4.70 & $\begin{array}{l}2.7 \text { to } \\
2.45\end{array}$ & $\begin{array}{l}\text { Movement } \\
\text { of Plasma }\end{array}$ \\
\hline 7 & 8 & 2.0 & 21.5 & 4.80 & 2.45 & B probe \\
\hline
\end{tabular}




\section{FIGURE CAPTIONS}

Fig. 1. The energy confinement time measured during NBI at the time of peak neutron emission for sequence 1 supershots. The various operating regimes described in the text are separated by vertical lines as well as by different symbols. Density traces used to indicate relative pellet and NBI times are shown as inserts. In these inserts, pellet injection is indicated by arrows while NBI is characterized by a one second rise in density with a roughly rectangular shape. Each insert is also associated with a particular symbol.

Fig. 2. The level of $\mathrm{Cll}$ emission (a. u.) in sequence 1 target plasmas measured $0.1 \mathrm{~s}$ before the beginning of NBI. The inserts, symbols and vertical lines are the same as for Fig. 1.

Fig. 3 The level of Lill emission (a. u.) in sequence 1 target plasmas. The inserts, symbols and vertical lines are the same as for Fig. 1.

Fig. 4 The levels of $\mathrm{Cll}$ (left scale) and $\mathrm{D} \alpha$ (right scale) emission (a. u.) measured during Ohmic discharges and during Ohmic discharges after the injection of two Li pellets (sequence 2). Shown in the insert is a density trace from one of the initial Ohmic discharges and from one of the last discharges in the pelletinjection series. The carbon emission is represented with $(O)$ 's while the $D \alpha$ emission is represented with $(X)$ 's.

Fig. 5 The energy confinement times for sequence 3 supershots. This sequence was run immediately following the Ohmic preconditioning carried out in sequence 2 . The various operating regimes described in the text are separated by vertical lines as well as by different symbols. Density traces used to indicate relative pellet and $\mathrm{NBI}$ times are shown as inserts. The last discharge had $a \mathrm{~B}$ and $a \mathrm{Li}$ pellet injected before $\mathrm{NBI}$ and is represented by an $(\mathrm{O})$. 
Fig. 6 The measured Lill emission associated with sequence 3 . The inserts, symbols and vertical lines are the same as for Fig. 5 .

Fig. 7 The energy confinement times for sequence 4 discharges. As a result of pellet conditioning, these discharges exhibited supershot-like confinement even at the high current level $(2.2$ MA) used in this sequence. The various operating regimes described in the text are separated by vertical lines as well as by different symbols. Density traces used to indicate relative pellet and NBI times are shown as inserts.

Fig. 8. The energy confinement time measured at the time of peak neutron emission for sequence 5 supershots. The various operating regimes described in the text are separated by vertical lines as well as by different symbols. Density traces used to indicate relative pellet and NBI times are shown as inserts. The types of pellets injected are also indicated.

Fig. 9. The (a) D $\alpha$ light, (b) Cll light, (c) plasma current, and (d) major radii for three Ohmic conditioning plasmas. The solid line is data taken after a sequence in which no pellets were injected and the $\mathrm{Cll}$ emission had evolved to a low level. The short dashed line is data taken after a sequence in which two Li pellets per discharge were injected at $2.0 \mathrm{~s}$ and $2.2 \mathrm{~s}$ (also the conditioning plasma just before the start of sequence 5 ). The long dashed line is data taken after a sequence in which the plasma was moved onto the inner wall limiter only for the deposition of the lithium (sequence 6).

Fig. 10. The time evolution of the Lill emission for three plasmas. The solid line is associated with the beginning of sequence 5 . The long dashed line is the first plasma after sequence 6 , and the short dashed line is the best TFTR supershot. It should be noted that $N B I$ began at $t=3.0 \mathrm{~s}$. 
Fig. 11. The energy confinement times for 1990 Supershots and 1992 post-boron-sputtering supershots plotted against beam power. Each plasma had $R=2.45 \mathrm{~m}, \mathrm{Ip}=2.0 \mathrm{MA}, \mathrm{Bt}=4.8 \mathrm{~T}$. The calculated $L$-mode scaling is also shown for reference.

Fig. 12. The gross energy confinement time at the time of peak neutron emission plotted against the Lill emission in the target plasma. The data is from sequence 1. The symbols are the same as those in Fig. 1.

Fig. 13. The gross energy confinement time, $\tau_{E}$, at the time of peak neutron emission plotted against the $D \alpha$ emission (a. u.) from the target plasma. The data is from sequence 1. The symbols are the same as those in Fig. 1.

Fig. 14. The gross energy confinement time, $\tau_{E}$, at the time of peak neutron emission plotted against the peakedness of the beam deposition, Hne. The data is from sequence 1. The symbols are the same as those in Fig. 1. 


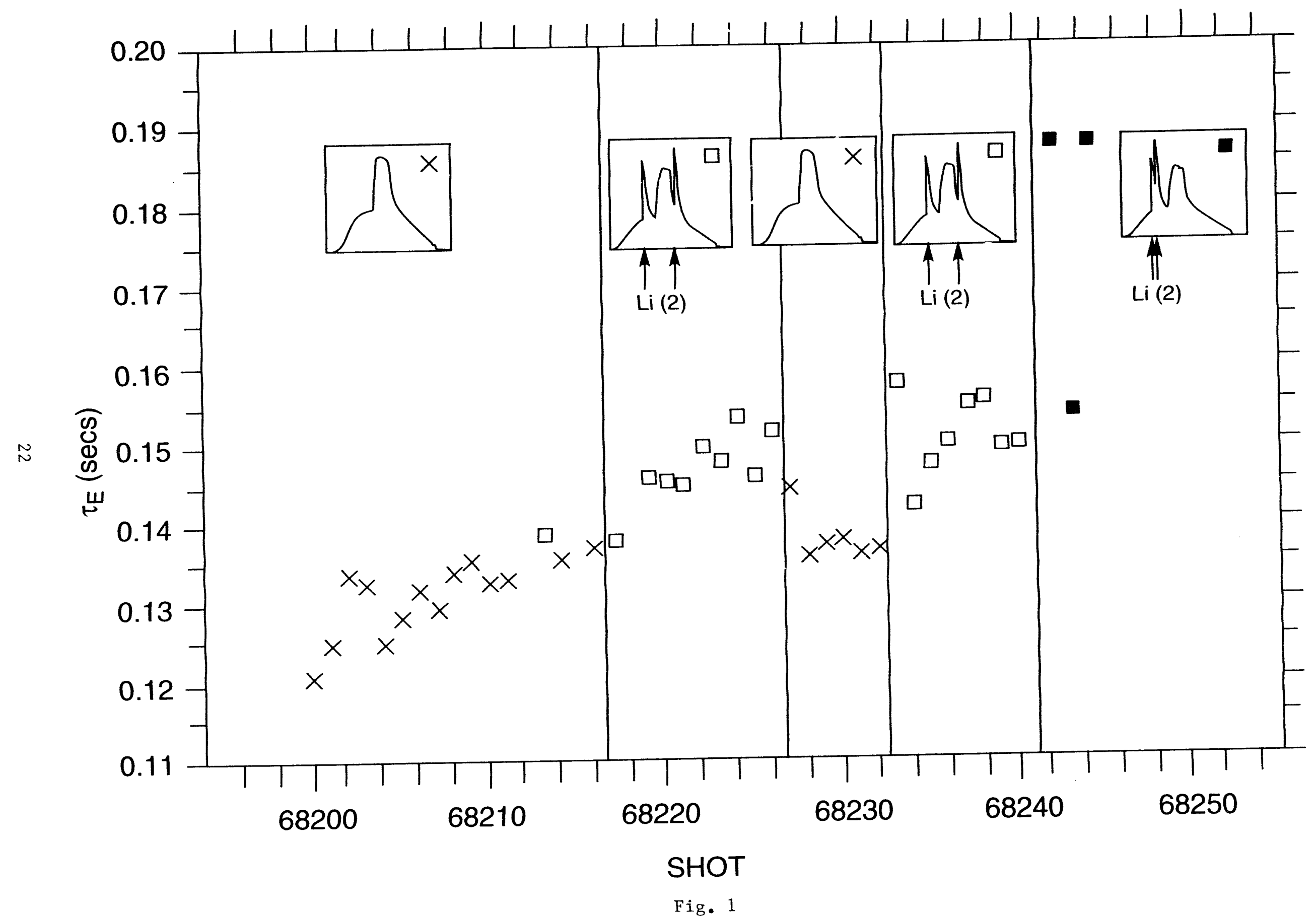




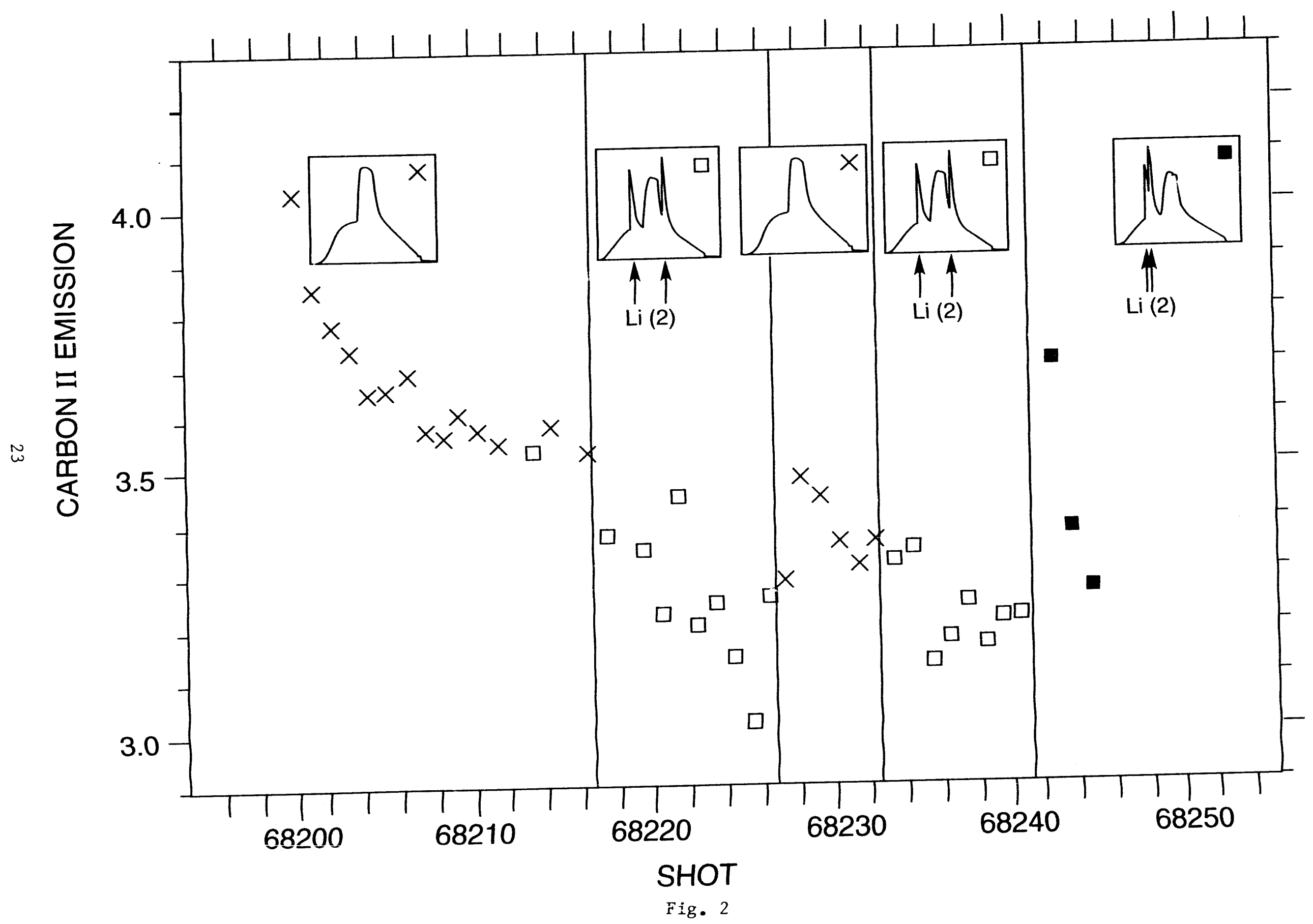




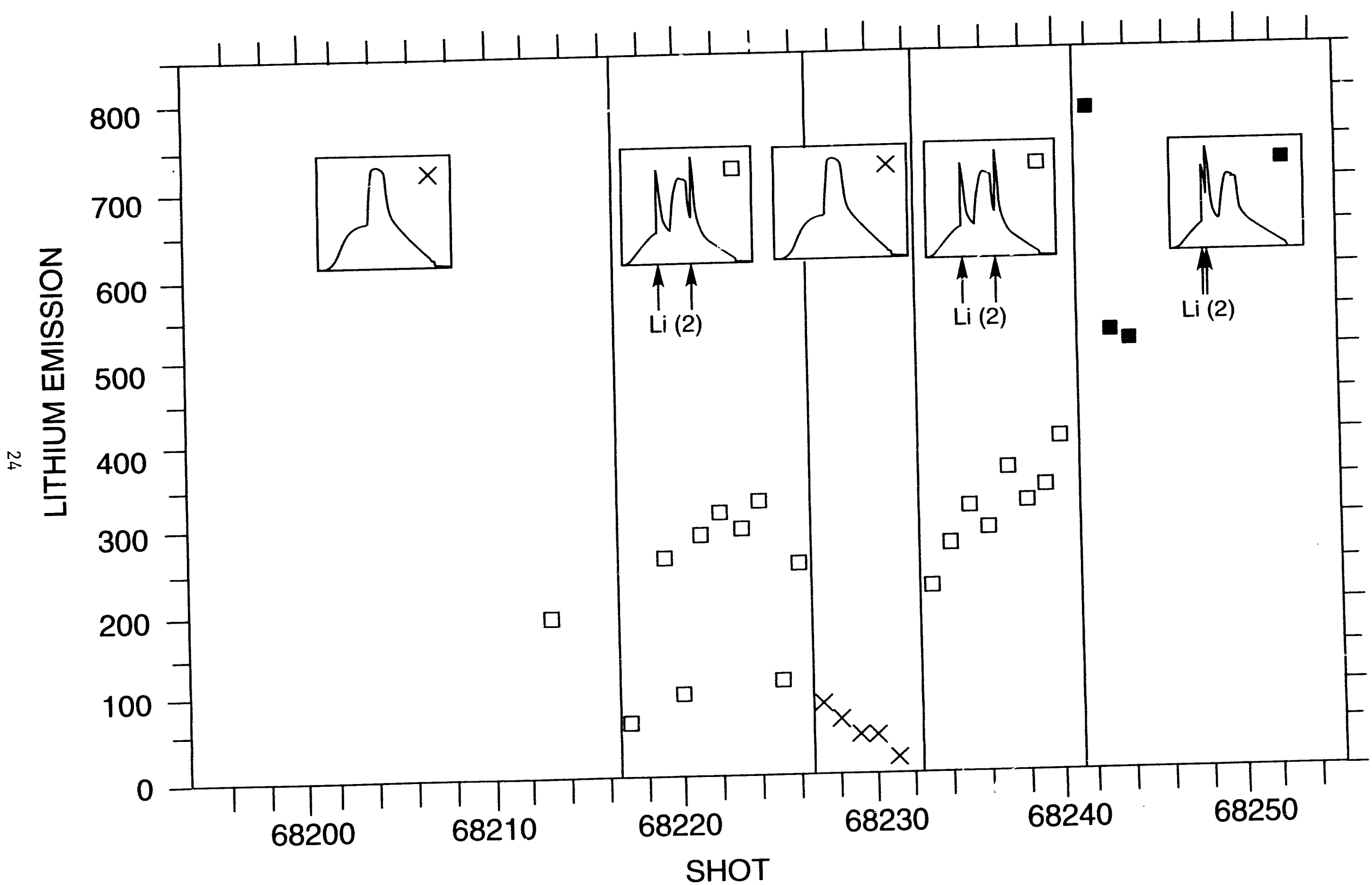

Fig. 3 
PPFL\# $93 \times 0132$

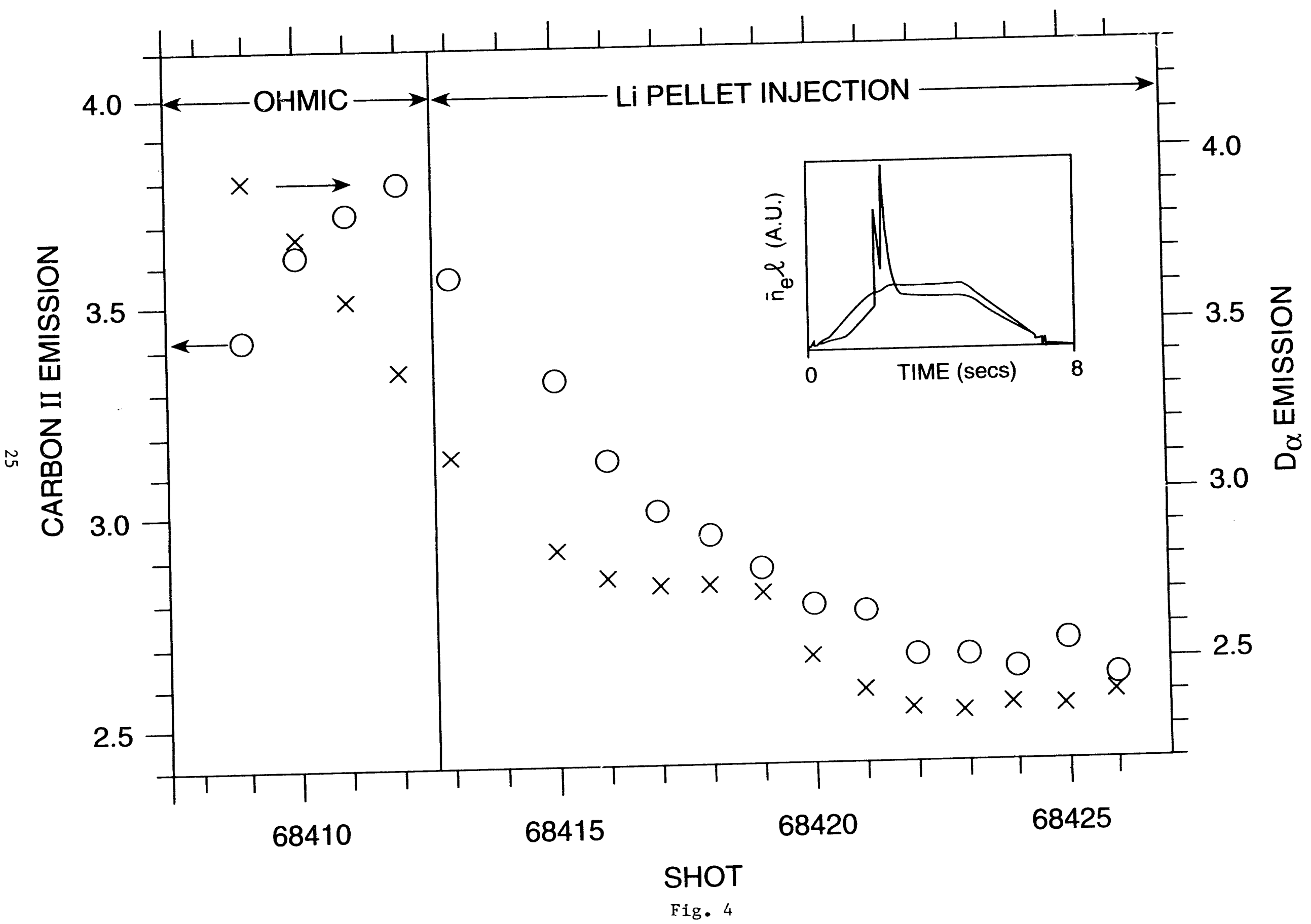




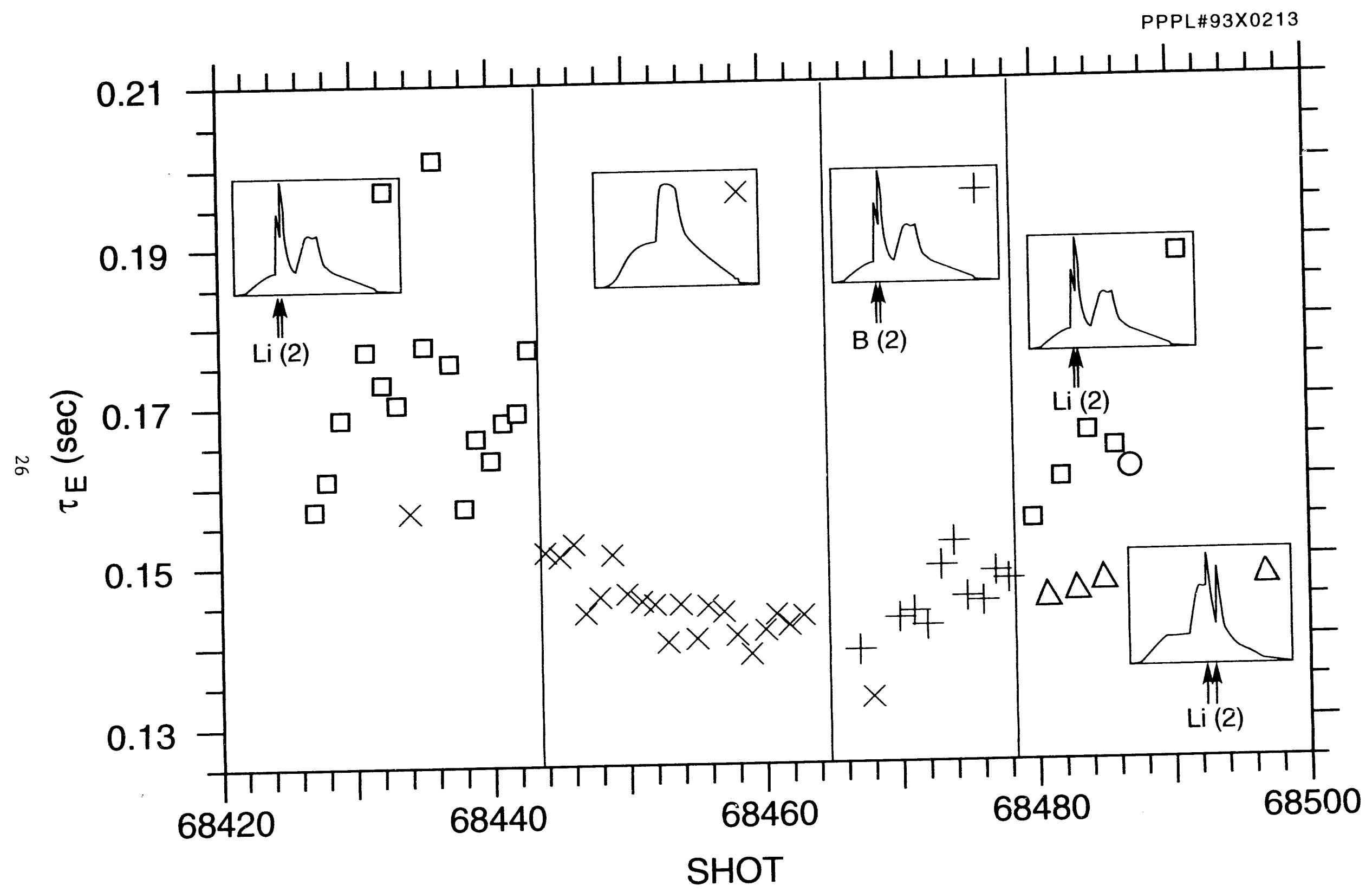

Fig. 5 


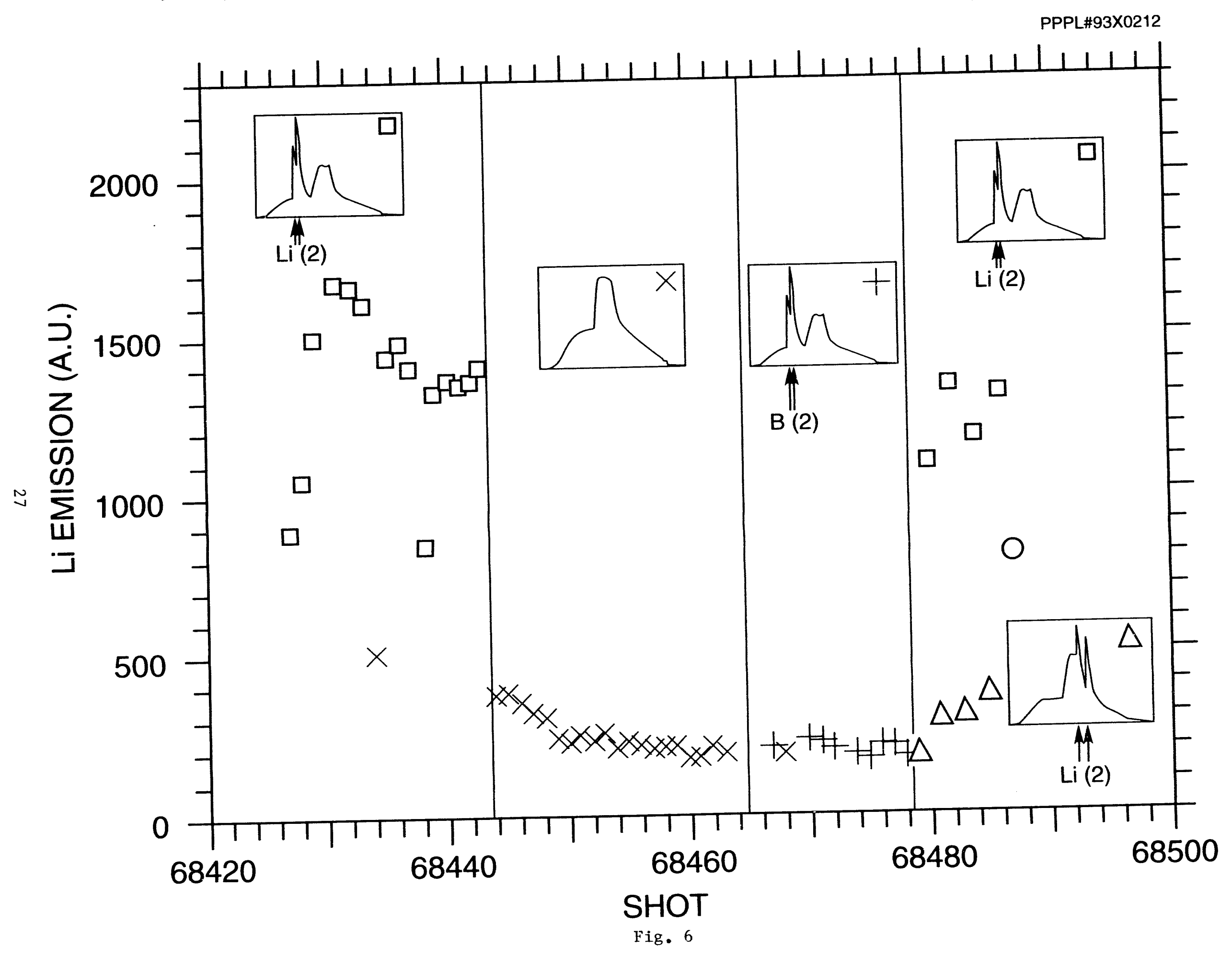




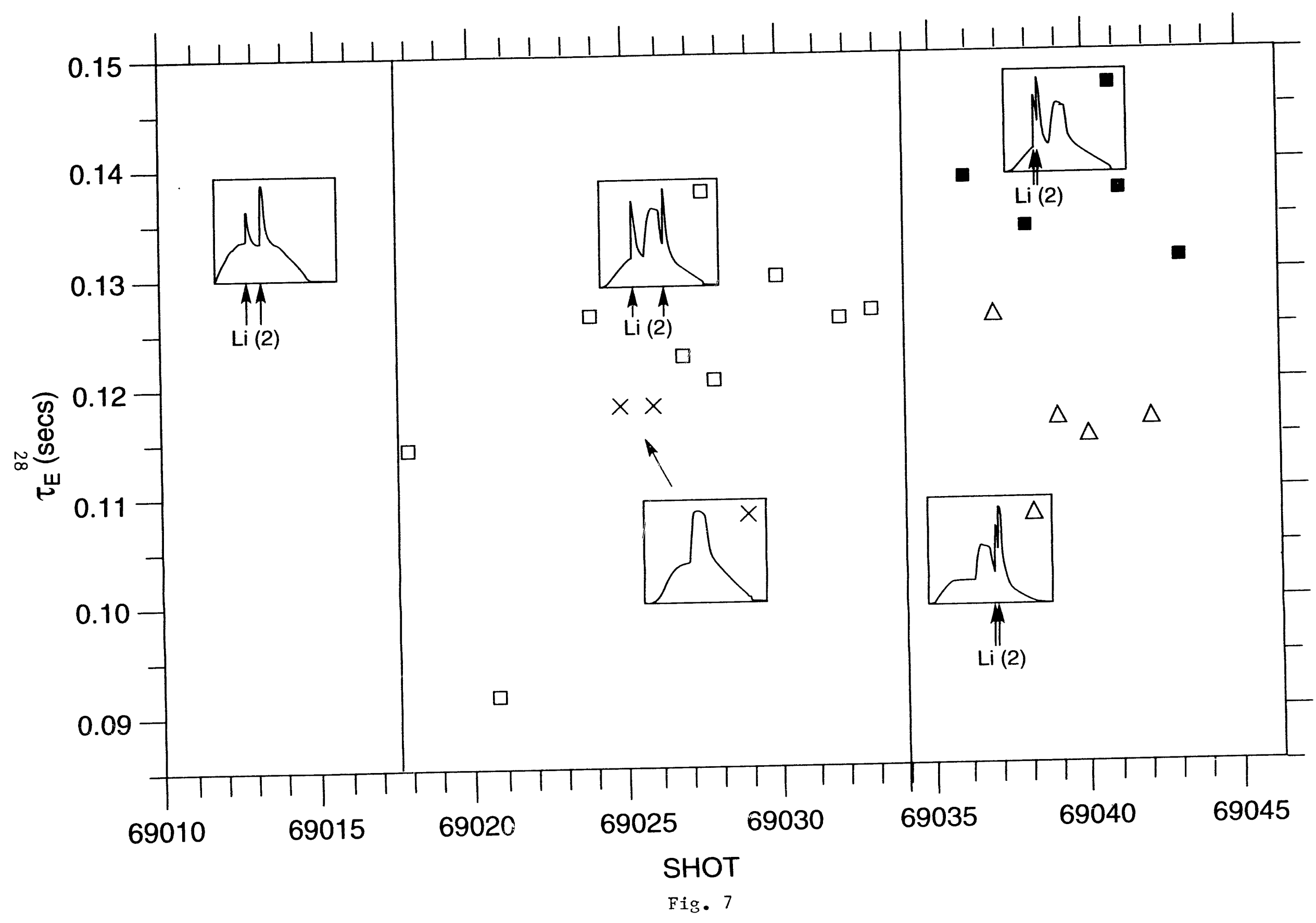


PPPL\#93X0138

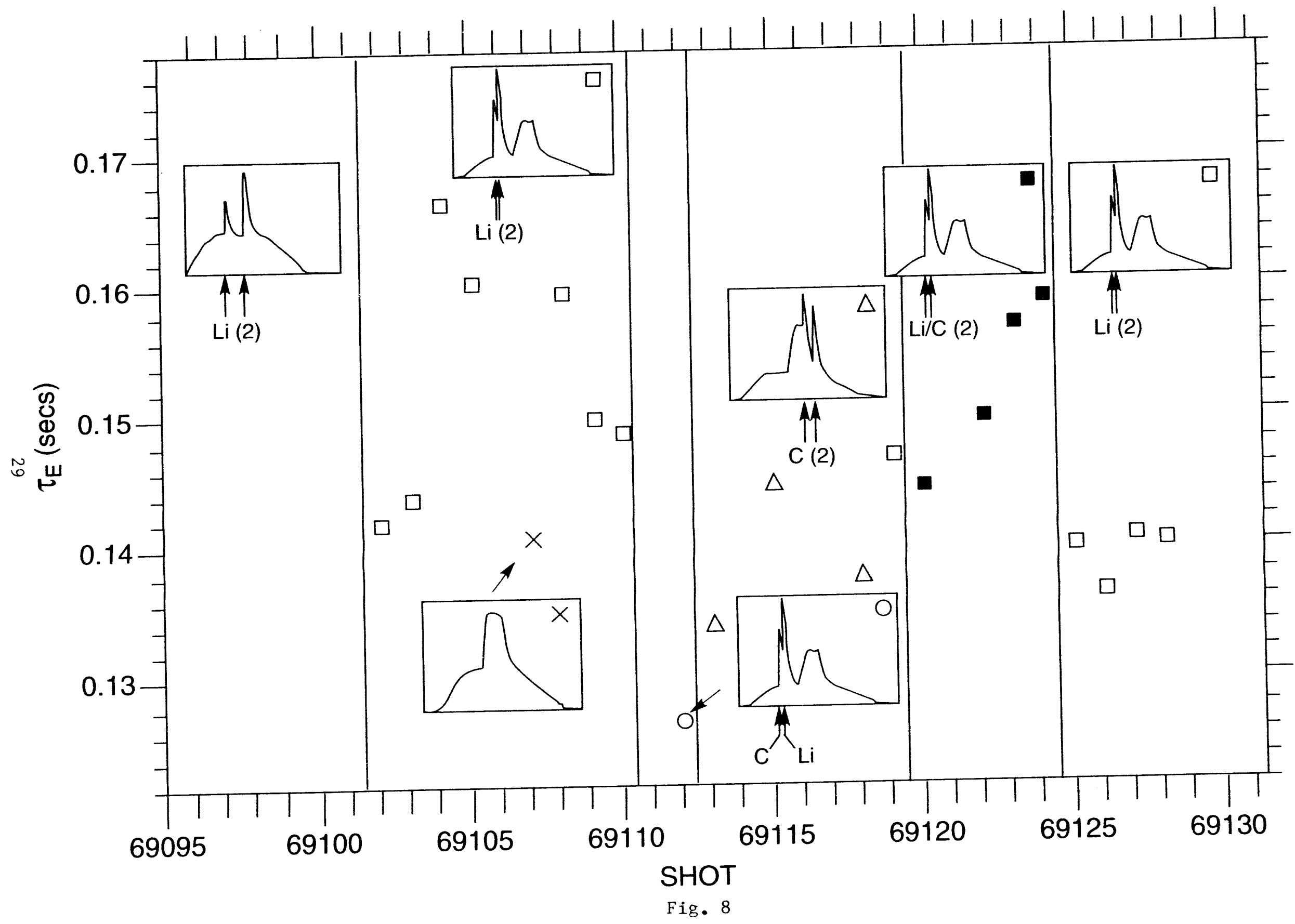


PPPL\#93X0207
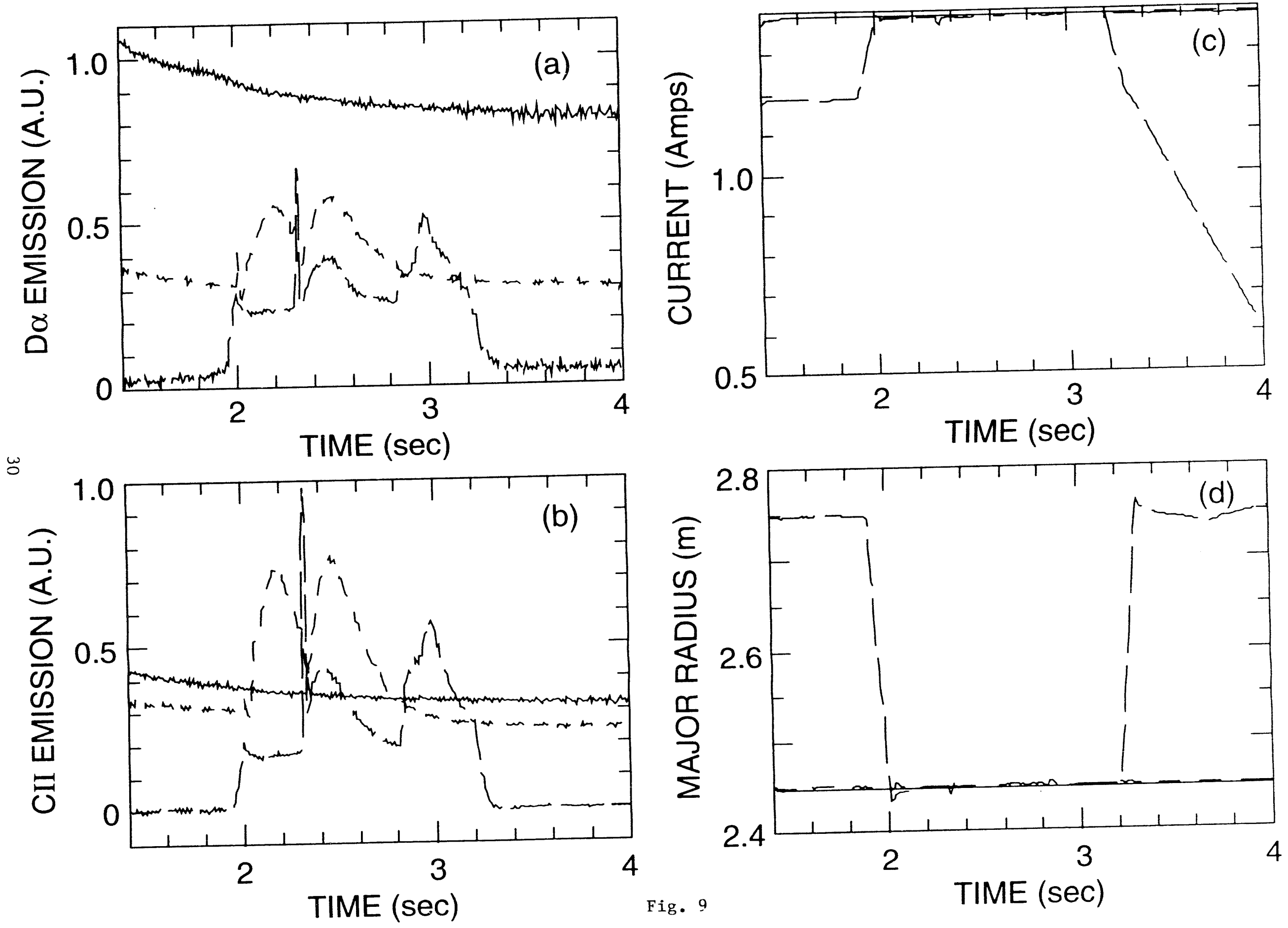
PPPL\#93X0208

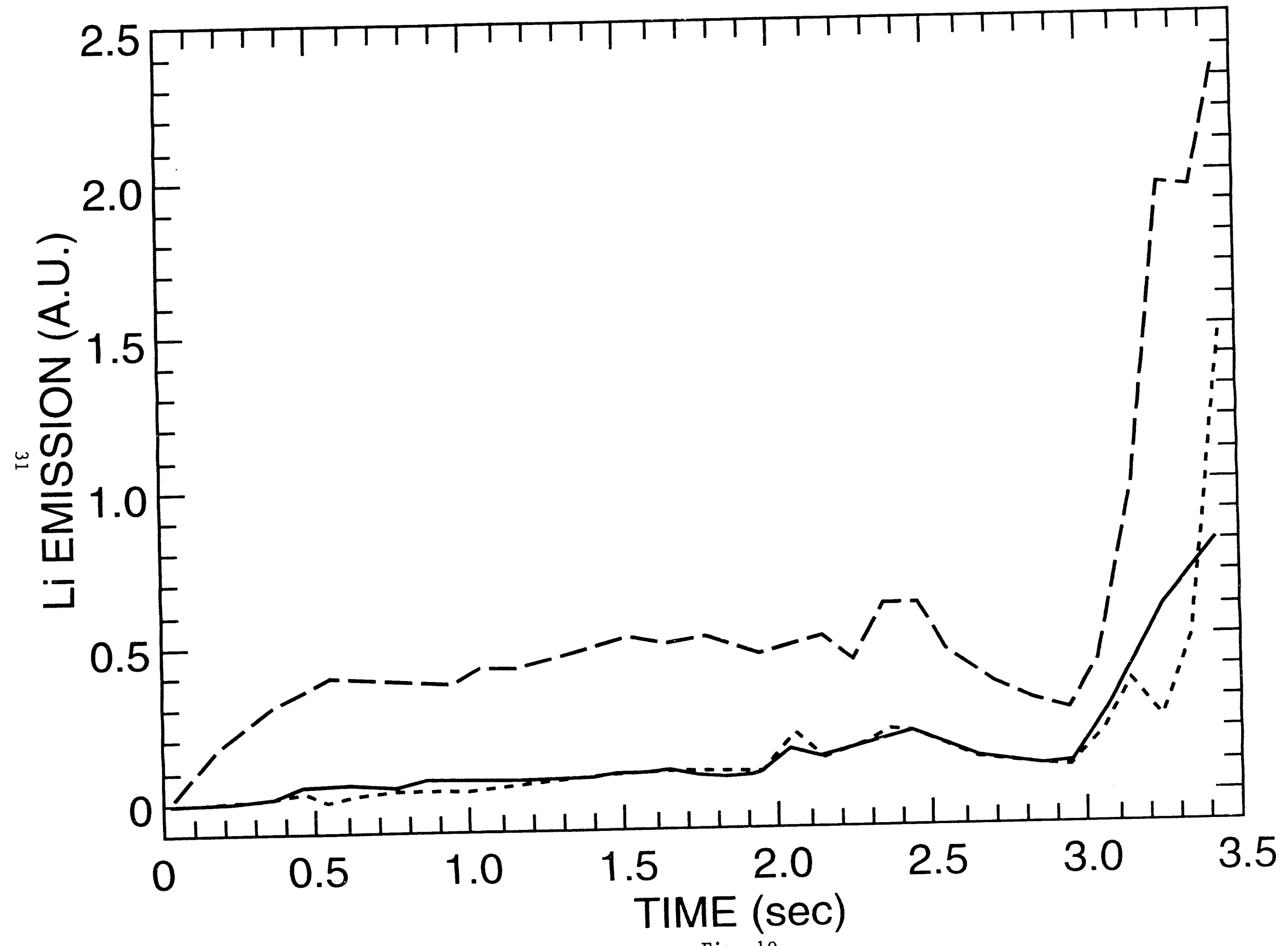

Fig. 10 
PPPL\#93X0131

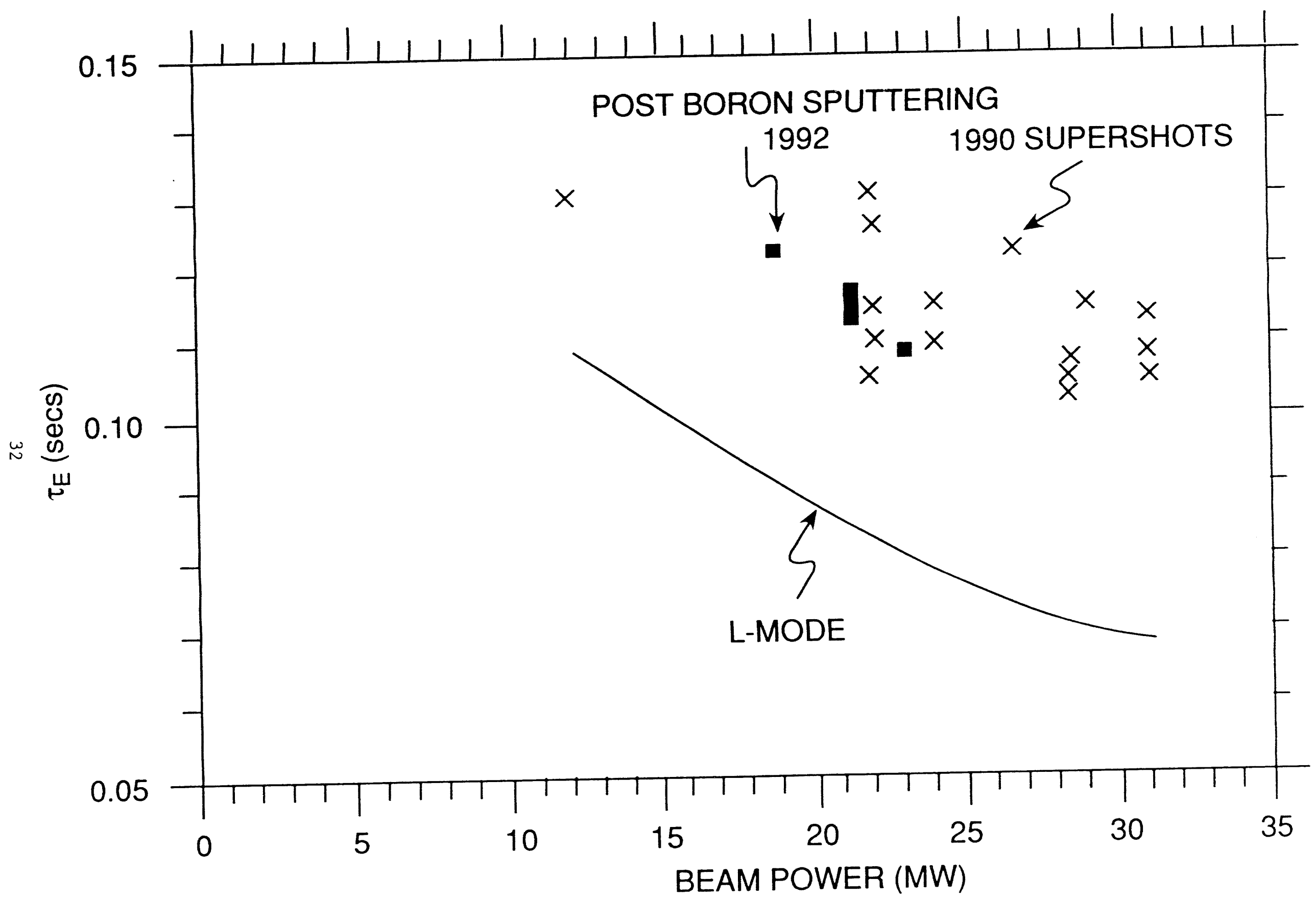

Fig. 11 


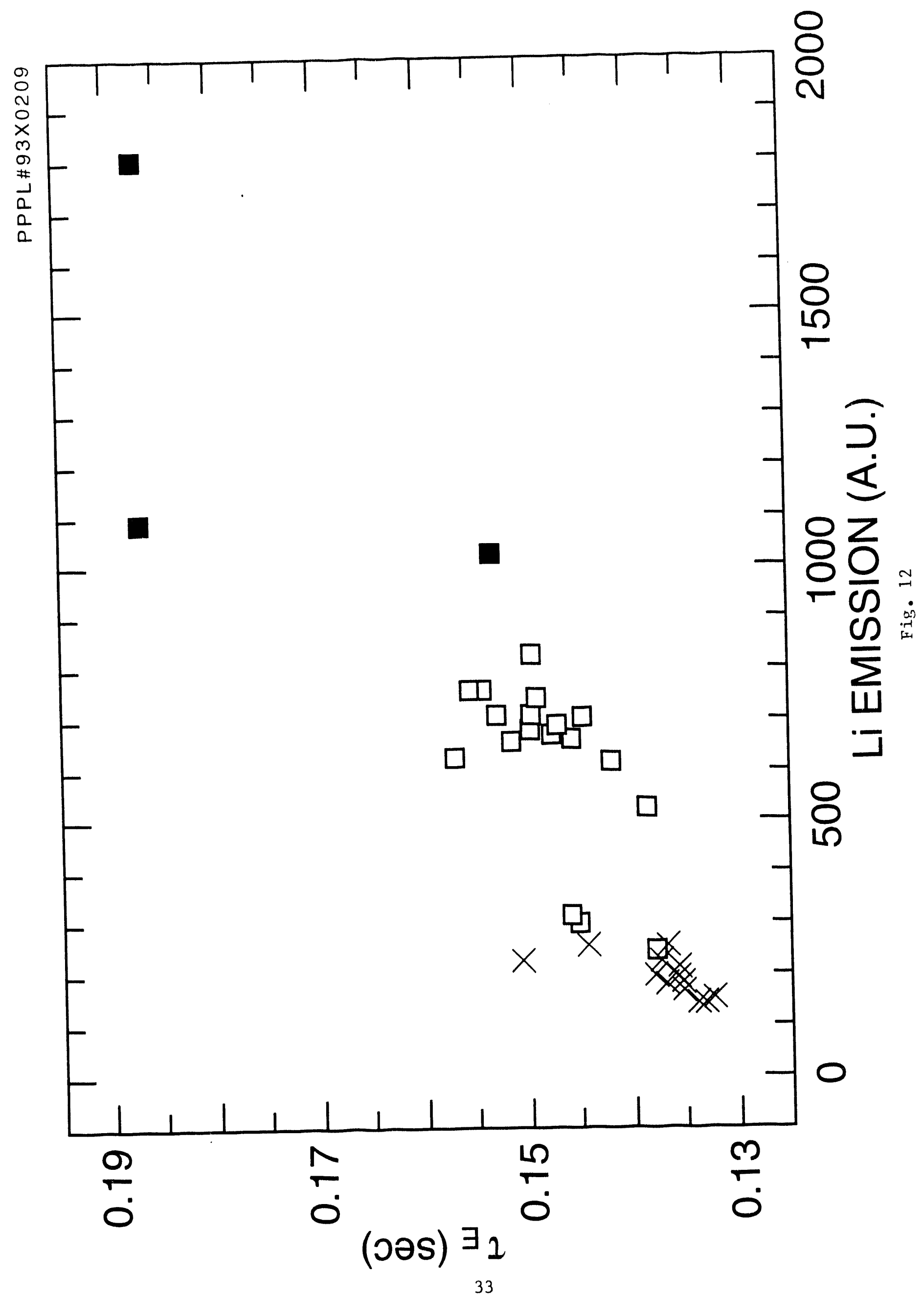




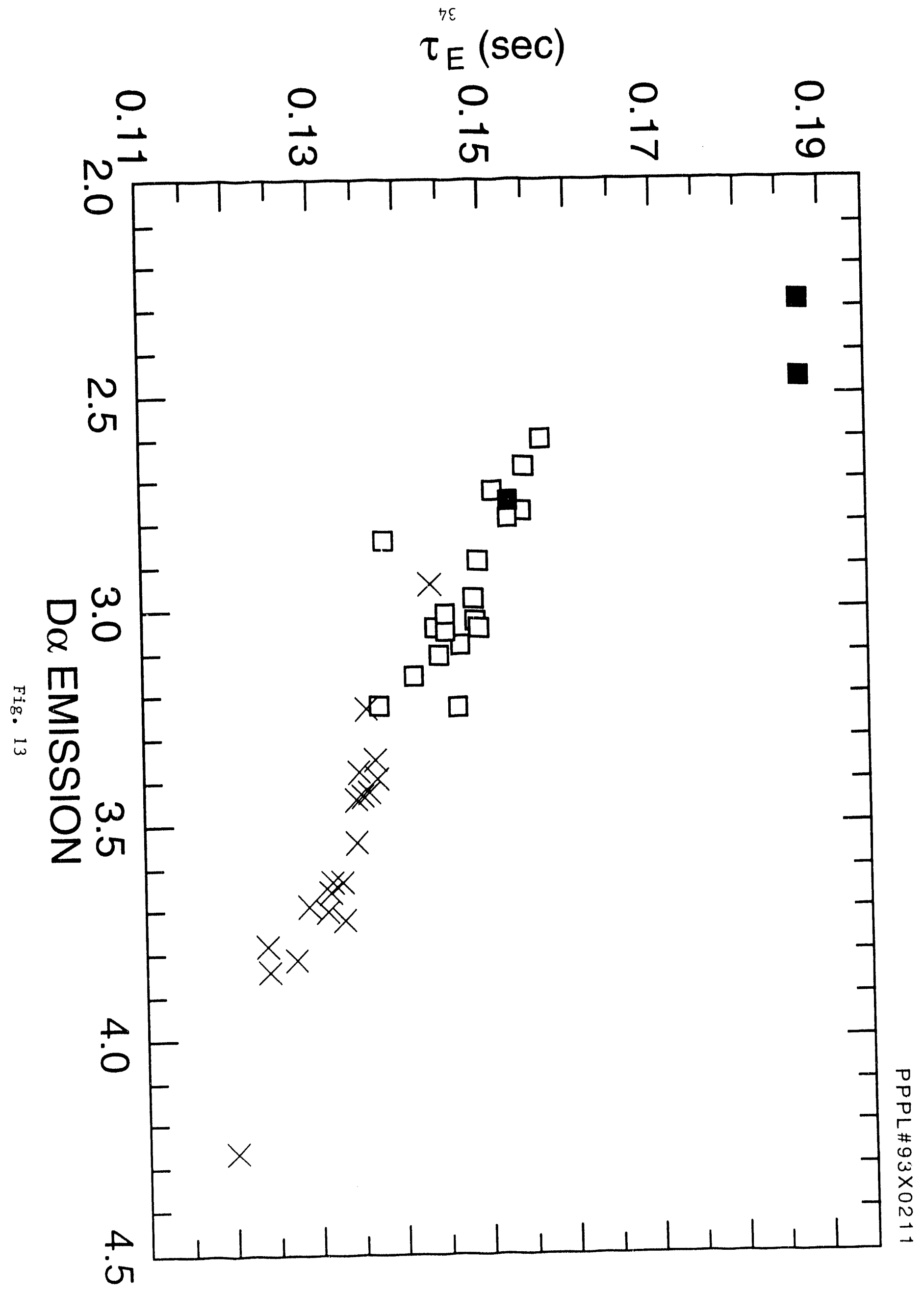




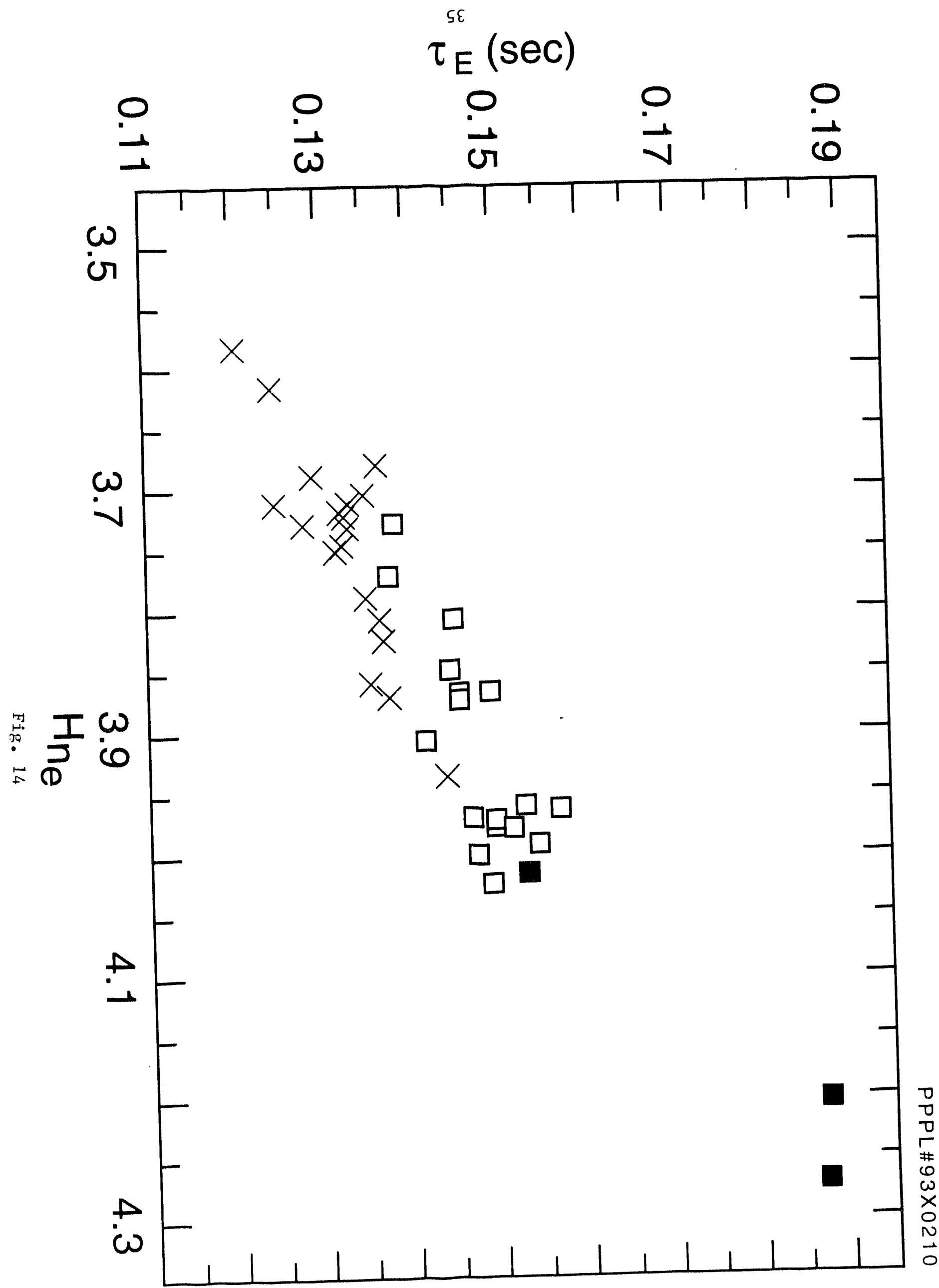




\section{EXTERNAL DISTRIBUTION IN ADDITION TO UC-420}

Dr. F. Paoloni, Univ. of Wollongong, AUSTRALIA

Prof. M.H. Brennan, Univ. of Syoney, AUSTRALIA

Plasma Research Lab., Australian Nat. Univ., AUSTRALIA

Prof. I.R. Jones, Flinders Univ, AUSTRALIA

Prof. F. Cap, Inst. for Theoretical Physics, AUSTRIA

Prot. M. Heindler, Institut tür Theoretische Physik, AUSTRIA

Prof. M. Goossens, Astronomisch Instituut, BELGIUM

Ecole Royale Militaire, Lab. de Phy. Plasmas, BELGIUM

Commission-European, DG. XII-Fusion Prog., BELGIUM

Prof. A. Bouciqué, Rijksuniversiteit Gent, BELGIUM

Dr. P.H. Sakanaka, Instituto Fisica, BRAZIL

Prof. Dr. I.C. Nascimento, Instituto Fisica, Sao Paulo, BRAZIL Instituto Nacional De Pesquisas Espaciais-INPE, BRAZIL

Documents Office, Atomic Energy of Canada Lid., Z....:DA

Ms. M. Morin, CCFWTokamak de Varennes, CANADA

Dr. M.P. Bachynski, MPB Technologies, Inc., CANADA

Dr. H.M. Skarsgard, Univ. of Saskatchewan, CANADA

Prof. J. Teichmann, Univ. of Montreal, CANADA

Prof. S.R. Sreenivasan, Univ. of Calgary, CANADA

Prof. T.W. Johnston, INRS-Energie, CANADA

Dr. R. Bolton, Centre canadion de fusion magnétique, CANADA

Dr. C.R. James, Univ. of Alberta, CANADA

Dr. P. Lukác, Komenského Universzita, CZECHO-SLOVAKIA

The Librarian, Cutham Laboratory, ENGLAND

Library, R61, Rutherford Appleton Laboratory, ENGLAND

Mrs. S.A. Hutchinson, JET Library, ENGLAND

Dr. S.C. Sharma, Univ. of South Pacific, FIJI ISLANDS

P. Mähönen, Univ. of Helsinki, FINLAND

Prot. M.N. Bussac, Ecole Polytechnique, FRANCE

C. Mouttet, Lab, de Physique des Milieux lonisés, FRANCE

J. Radet, CEN/CADARACHE - Bat 506, FRANCE

Prof. E. Economou, Univ. of Crete, GREECE

Ms. C. Rinni, Univ. of loannina, GREECE

Preprint Library, Hungarian Academy of Sa., HUNGARY

Dr. B. DasGupta, Saha Inst. of Nuclear Physics, INDIA

Dr. P. Kaw, Inst. for Plasma Research, INDIA

Dr. P. Rosenau, Israel Inst. of Technology, ISRAEL

Librarian, International Center for Theo Physics, ITALY

Miss C. De Palo, Associazione EURATOM-ENEA, ITALY

Dr. G. Grosso, Istituto di Fisica del Plasma, ITALY

Prof. G. Rostangni, Istituto Gas lonizzati Del Cnr, ITALY
Dr. H. Yamato, Toshiba Res \& Devel Center, JAPAN

Prof. I. Kawakami, Hiroshima Univ., JAPAN

Prof. K. Nishikawa, Hiroshima Univ., JAPAN

Librarian, Naka Fusion Research Establishment, JAERI, IAPAN

Director, Japan Atomic Energy Research Inst., JAPAN

Prot. S. Itoh, Kyushu Univ., JAPAN

Research Info. Ctr., National Instit. for Fusion Science, JAPAN

Prof. S. Tanaka, Kyoto Univ., JAPAN

Library, Kyoto Univ., JAPAN

Prof. N. Inove, Univ. of Tokyo, JAPAN

Secretary, Plasma Section, Electrotechnical Lab., JAPAN

S. Mori, Technical Advisor, JAERI, JAPAN

Dr. O. Mitarai, Kumamoto Inst. of Technology, JAPAN

Dr. G.S. Lee, Korea Basic Sci. Ctr., KOREA

J. Hyeon-Sook, Korea Atomic Energy Research Inst., KOREA

D.I. Choi, The Korea Adv. Inst. of Sci. \& Tech., KOREA

Prof. B.S. Liley, Univ. of Waikato, NEW ZEALAND

Inst of Physics, Chinese Acad Sci PEOPLE'S REP. OF CHINA

Library, Inst. of Plasma Physics, PEOPLE'S REP. OF CHINA

Tsinghua Univ. Library, PEOPLE'S REPUBLIC OF CHINA

2. Li, S.W. Inst Physias, PEOPLE'S REPUBLIC OF CHINA

Prof. J.A.C. Cabral, Instituto Superior Tecnico, PORTUGAL

Prof. M.A. Hellberg, Univ. of Natal, S. AFRICA

Prof. D.E. Kim, Pohang Inst. of Sci. \& Tech., SO. KOREA

Prof. C.I.E.M.A.T, Fusion Division Library, SPAIN

Dr. L. Stenflo, Univ. of UMEA, SWEDEN

Library, Royal Inst. of Technology, SWEDEN

Prot. H. Wilhelmson, Chalmers Univ. of Tech., SWEDEN

Centre Phys. Des Plasmas, Ecole Polytech, SWITZERLAND

Bibliotheek, Inst. Voor Plasma-Fysica, THE NETHERLANDS

Asst. Prot. Dr. S. Cakir, Middle East Tech. Univ., TURKEY

Dr. V.A. Glukhikh,Sci. Res. Inst. Electrophys.I Apparatus, USSR

Dr. D.D. Ryutov, Siberian Branch of Academy of Sci., USSR

Dr. G.A. Eliseev, I.V. Kurchatov Inst., USSR

Librarian, The Ukr.SSR Academy of Sciences, USSR

Dr. L.M. Kovrizhnykh, Inst. of General Physics, USSR

Kernforschungsanlage GmbH, Zentralbibliothek, W. GERMANY

Bibliothek, Inst. Für Plasmatorschung. W. GERMANY

Prof. K. Schindler, Ruhr-Universitár Bochum, W. GERMANY

Dr. F. Wagner, (ASDEX), Max-Planck-Institut, W. GERMANY

Librarian, Max-Planck-Institut, W. GERMANY 

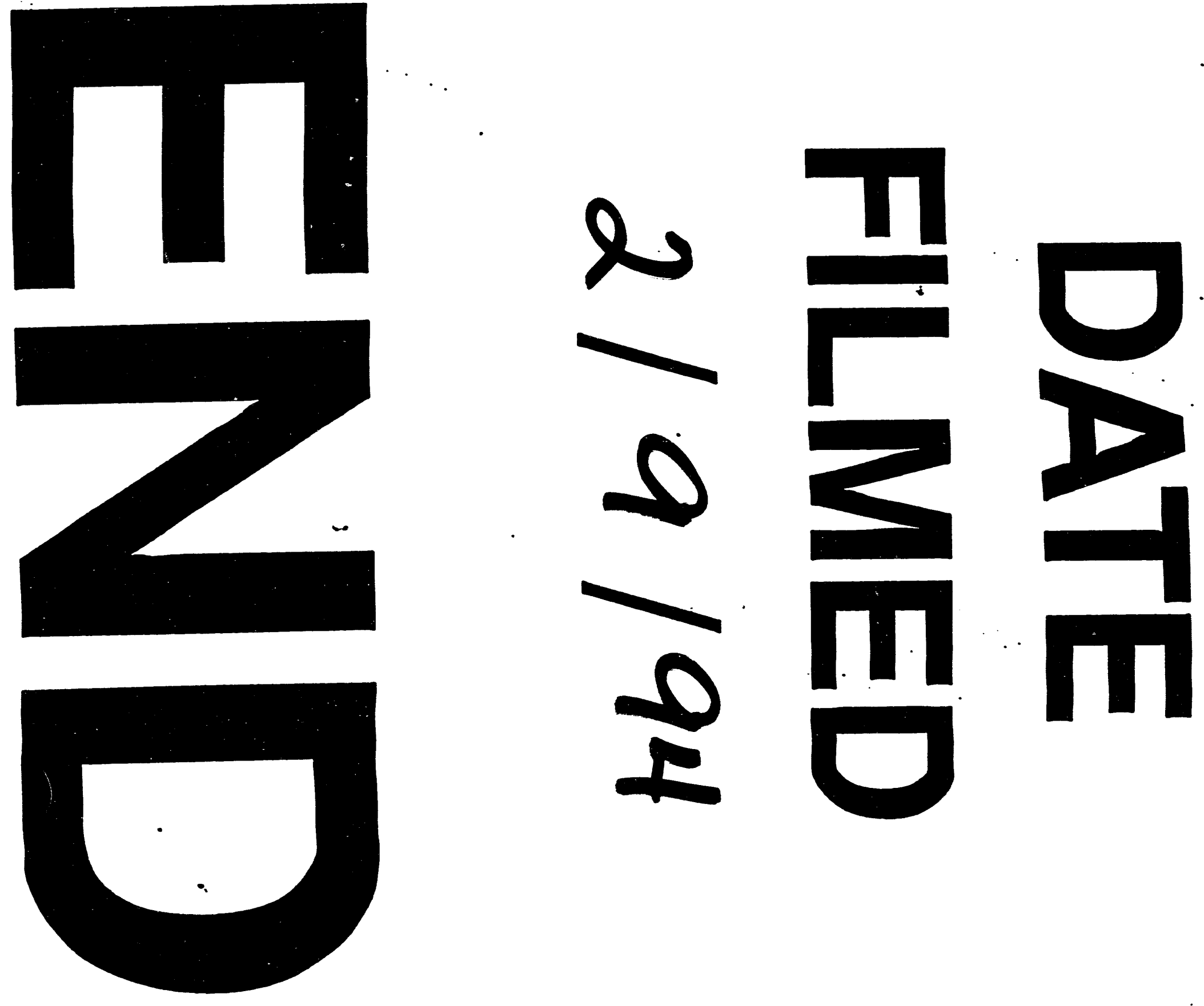